\title{
A Transferable Force Field for Predicting Adsorption and Diffusion of Hydrocarbons and Small Molecules in Silica Zeolites with Coupled Cluster Accuracy: Supporting Information
}

John M. Findley ${ }^{1}$, Salah Eddine Boulfelfel ${ }^{1}$, Hanjun Fang ${ }^{1}$, Giovanni Muraro ${ }^{2}$, Peter I. Ravikovitch $^{2 \dagger}$, and David S. Sholl ${ }^{1 \dagger}$

${ }^{1}$ School of Chemical and Biomolecular Engineering, Georgia Institute of Technology, Atlanta, Georgia 30332-0100, United States

${ }^{2}$ Corporate Strategic Research, ExxonMobil Research and Engineering, 1545 Route 22 East, Annandale, New Jersey 08801, United States

${ }^{\dagger}+1-908-335-2280$, peter.ravikovitch@exxonmobil.com $\$+1-404-894-2822$, david.sholl@,chbe.gatech.edu 


\section{Table of Contents}

S1. DFT/CC (density functional theory/coupled cluster) method for alkanes/alkenes $\cdots$ zeolite interactions..................................................................................................... 3

S2. Additional adsorption isotherms validation ................................................................................ 11

S3. Literature force fields of methane and ethane in silica zeolites........................................... 16

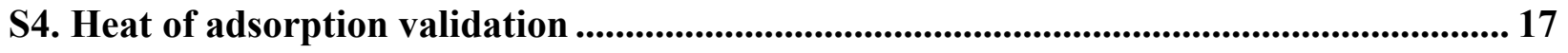

S5. FF development for $\mathrm{H}_{2} \mathrm{O}$ in pure silica zeolites....................................................................... 21

S6. Additional diffusion validation ....................................................................................................... 23

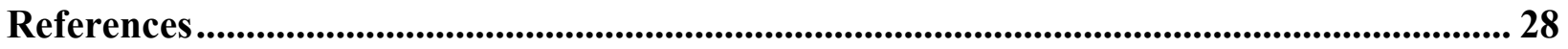


S1. DFT/CC (density functional theory/coupled cluster) method for alkanes/alkenes $\cdots$ zeolite interactions

The DFT/CC method was proposed by Nachtigall and co-workers for an accurate description of weakly bound molecular systems. ${ }^{1}$ This method is based on estimating the DFT error, and then correcting the DFT energies for periodic systems. Here $\Delta E^{\mathrm{DFT} / \mathrm{CC}}$ is defined as the difference between DFT and accurate $\operatorname{CCSD}(\mathrm{T})$ interaction energies on molecular cluster. This method is similar to DFT-D class of methods but with a key difference: the artificial assumption about the particular form of the $\Delta E$ correction is removed. Instead, all the deficiencies of the DFT method for the description of weakly interacting systems are defined purely numerically (using an interpolation method), by correcting the DFT interaction energies to $\operatorname{CCSD}(\mathrm{T})$ accuracy.

The main assumption of the method is that $\Delta E^{\mathrm{DFT} / \mathrm{CC}}$ can be represented as pairwise representation using the following equation

$$
\Delta E^{D F T / C C}=\sum_{i}^{N_{a}} \sum_{j}^{N_{b}} \varepsilon_{i j}\left(R_{i j}\right)
$$

where $N_{a}$ and $N_{b}$ are the numbers of atoms of the corresponding monomers, $\varepsilon_{i j}$ are the DFT/CC correction functions, and $R_{i j}$ is the intermolecular atomic distance between atoms $i$ and $j$. The correction functions are obtained from a set of energies calculated at $\operatorname{CCSD}(\mathrm{T}) / \mathrm{CBS}(\mathrm{CBS}=$ complete basis sets) and PBE/AV5Z levels for a suitable reference set of molecules or clusters $\left(\mathrm{C}_{\mathrm{x}} \mathrm{H}_{\mathrm{y}} \cdots \mathrm{H}_{2}, \mathrm{C}_{\mathrm{x}} \mathrm{H}_{\mathrm{y}} \cdots \mathrm{H}_{2} \mathrm{O}\right.$, and $\mathrm{C}_{\mathrm{x}} \mathrm{H}_{\mathrm{y}} \cdots \mathrm{Si}(\mathrm{OH})_{4}$, where $\mathrm{x}=1,2,3$, 4, and 5 , and $\mathrm{y}=2 \mathrm{x}+2$ for alkanes and $\mathrm{y}=2 \mathrm{x}$ for alkenes) by means of the Reciprocal Power Reproducing Kernel Hilbert Space Interpolation (RP-RKHS) as summarized below. In short, the RP-RKSH interpolation scheme is used to decompose $\Delta \mathrm{E}$ into $\varepsilon_{\mathrm{CH}}\left(\mathrm{R}_{\mathrm{CH}}\right)$ and $\varepsilon_{\mathrm{HH}}\left(\mathrm{R}_{\mathrm{HH}}\right)$ for $\mathrm{C}_{\mathrm{x}} \mathrm{H}_{\mathrm{y}} \cdots \mathrm{H}_{2}, \varepsilon_{\mathrm{CO}}\left(\mathrm{R}_{\mathrm{CO}}\right)$ and 
$\varepsilon \mathrm{HO}\left(\mathrm{R}_{\mathrm{HO}}\right)$ for $\mathrm{C}_{\mathrm{x}} \mathrm{H}_{\mathrm{y}} \cdots \mathrm{H}_{2} \mathrm{O}$, and $\varepsilon_{\mathrm{CSi}}\left(\mathrm{R}_{\mathrm{CSi}}\right)$ and $\varepsilon_{\mathrm{HSi}}\left(\mathrm{R}_{\mathrm{HSi}}\right)$ for $\mathrm{C}_{\mathrm{x}} \mathrm{H}_{\mathrm{y}} \cdots \mathrm{Si}(\mathrm{OH})_{4}$. These reference sets are chosen because precise calculations at the $\operatorname{CCSD}(\mathrm{T})$ level with sufficiently flexible basis sets are feasible.

In our previous work, we studied $\mathrm{CH}_{4}$ interacting with $\mathrm{H}_{2}, \mathrm{H}_{2} \mathrm{O}$, and $\mathrm{Si}(\mathrm{OH})_{4}$, and obtained the DFT/CC correction functions between $\mathrm{CH}_{4}$ sp $^{3}$ and $\mathrm{H}, \mathrm{O}$, and $\mathrm{Si}$. The $\mathrm{CH}_{4} \cdots \mathrm{H}_{2}$ reference system (Figure S1 (a) and S1 (b)) provides the $\varepsilon_{\mathrm{CH}}$ and $\varepsilon_{\mathrm{HH}}$ correction functions. The $\mathrm{CH}_{4} \cdots \mathrm{H}_{2} \mathrm{O}$ reference system (Figure S1 (c) and S1 (d)) provides $\varepsilon \mathrm{CO}$ and $\varepsilon \mathrm{HO}$ correction functions using $\varepsilon_{\mathrm{CH}}$ and $\varepsilon_{\mathrm{HH}}$ obtained previously for $\mathrm{CH}_{4} \cdots \mathrm{H}_{2}$. The $\mathrm{CH}_{4} \cdots \mathrm{Si}(\mathrm{OH})_{4}$ reference system (Figure S1 (e) and S1 (f)) provided $\varepsilon_{\mathrm{CS} i}$ and $\varepsilon_{\mathrm{OSi}}$ correction functions using $\varepsilon_{\mathrm{CH}}$ and $\varepsilon_{\mathrm{HH}}$ obtained previously for $\mathrm{CH}_{4} \cdots \mathrm{H}_{2}$ and $\varepsilon \mathrm{CO}$ and $\varepsilon \mathrm{HO}$ obtained previously for $\mathrm{CH}_{4} \cdots \mathrm{H}_{2} \mathrm{O}$.

Here, we work on the other small alkanes and alkenes including $\mathrm{C}_{2} \mathrm{H}_{6}, \mathrm{C}_{3} \mathrm{H}_{8}$, iso- $\mathrm{C}_{4} \mathrm{H}_{10}$, neo- $\mathrm{C}_{5} \mathrm{H}_{12}, \mathrm{C}_{2} \mathrm{H}_{4}, \mathrm{C}_{3} \mathrm{H}_{6}$, and iso- $\mathrm{C}_{4} \mathrm{H}_{8}$, and extend the DFT/CC correction functions for $\mathrm{CH}_{3} \mathrm{sp}^{3}$, $\mathrm{CH}_{2} \_\mathrm{sp}^{3}, \mathrm{CH} \_\mathrm{sp}^{3}, \mathrm{C} \_\mathrm{sp}^{3}, \mathrm{CH}_{2} \mathrm{sp}^{2}, \mathrm{CH} \mathrm{sp}^{2}$, and $\mathrm{C} \_\mathrm{sp}^{2}$ with $\mathrm{H}, \mathrm{O}$, and $\mathrm{Si}$. For these alkanes and alkenes, rather than derive the DFT/CC correction functions for both $\mathrm{C}$ and $\mathrm{H}$ atoms of $\mathrm{C}_{2} \mathrm{H}_{6}$, $\mathrm{C}_{3} \mathrm{H}_{8}$, iso- $\mathrm{C}_{4} \mathrm{H}_{10}, \mathrm{C}_{2} \mathrm{H}_{4}, \mathrm{C}_{3} \mathrm{H}_{6}$, and iso- $\mathrm{C}_{4} \mathrm{H}_{8}$, we retain the correction functions of the $\mathrm{H}$ atom for $\mathrm{CH}_{3} \_\mathrm{sp}^{3}, \mathrm{CH}_{2} \_\mathrm{sp}^{3}, \mathrm{CH} \_\mathrm{sp}^{3}, \mathrm{CH}_{2} \mathrm{sp}^{2}$, and $\mathrm{CH}_{-} \mathrm{sp}^{2}$ groups as the ones from $\mathrm{CH}_{4} \_\mathrm{sp}^{3}$, and only develop the correction functions of the $\mathrm{C}$ atom for each group. The reference systems for these alkanes and alkenes are shown in Figures S2-S8. 
(a)

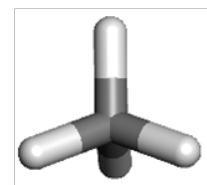

(b)

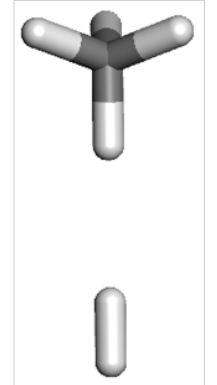

(c)
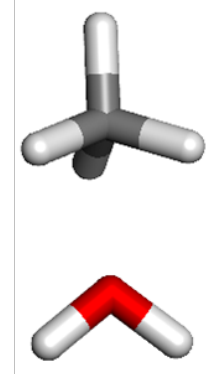

(d)

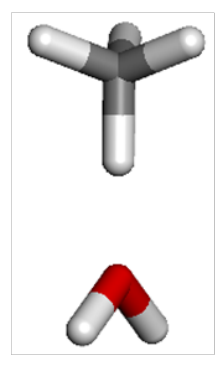

(e)

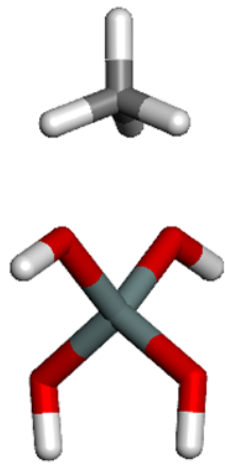

(f)

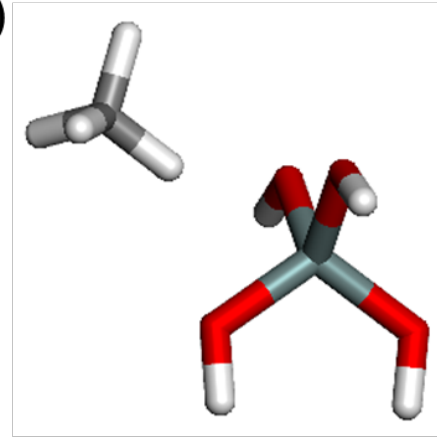

Figure S1: Definition of the reference set used for the generation of the DFT/CC correction functions: (a, b) $\mathrm{CH}_{4} \cdots \mathrm{H}_{2}\left(\mathrm{C}_{3 \mathrm{v}}\right)$, (c, d) $\mathrm{CH}_{4} \cdots \mathrm{H}_{2} \mathrm{O}\left(\mathrm{C}_{\mathrm{s}}\right)$, and $(\mathrm{e}, \mathrm{f}) \mathrm{CH}_{4} \cdots \mathrm{Si}(\mathrm{OH})_{4}\left(\mathrm{C}_{\mathrm{s}}\right)$. The $\mathrm{C}, \mathrm{O}$, $\mathrm{H}$, and $\mathrm{Si}$ atoms are depicted in grey, red, white, and dark cyan color, respectively. The figure is from our previous study. ${ }^{2}$

(a)

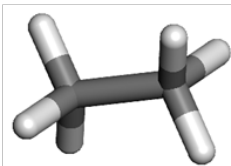

Q (b)
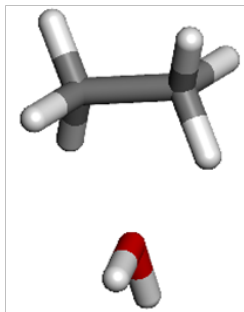

(c)

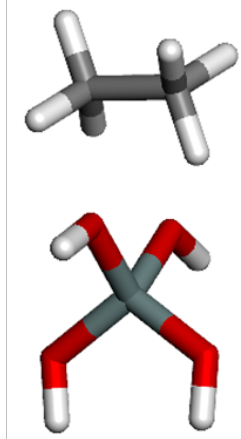

Figure S2: Definition of the reference set used for the generation of the DFT/CC correction functions: (a) $\mathrm{C}_{2} \mathrm{H}_{6} \cdots \mathrm{H}_{2}\left(\mathrm{C}_{\mathrm{s}}\right)$, (b) $\mathrm{C}_{2} \mathrm{H}_{6} \cdots \mathrm{H}_{2} \mathrm{O}$ (c), and (c) $\mathrm{C}_{2} \mathrm{H}_{6} \cdots \mathrm{Si}(\mathrm{OH})_{4}\left(\mathrm{C}_{\mathrm{s}}\right)$. The $\mathrm{C}, \mathrm{O}, \mathrm{H}$, and $\mathrm{Si}$ atoms are depicted in grey, red, white, and dark cyan color, respectively. 
(a)

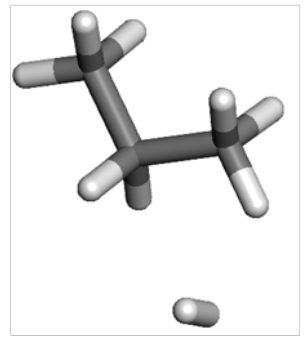

(b)

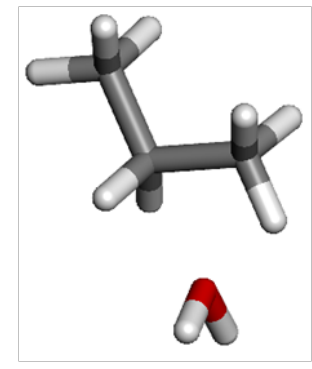

(c)

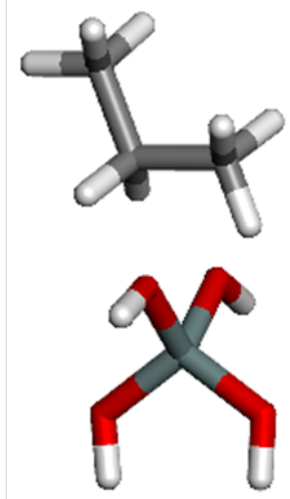

Figure S3: Definition of the reference set used for the generation of the DFT/CC correction functions: (a) $\mathrm{C}_{3} \mathrm{H}_{8} \cdots \mathrm{H}_{2}\left(\mathrm{C}_{\mathrm{s}}\right)$, (b) $\mathrm{C}_{3} \mathrm{H}_{8} \cdots \mathrm{H}_{2} \mathrm{O}\left(\mathrm{C}_{\mathrm{s}}\right.$ ), and (c) $\mathrm{C}_{3} \mathrm{H}_{8} \cdots \mathrm{Si}(\mathrm{OH})_{4}\left(\mathrm{C}_{\mathrm{s}}\right)$. The $\mathrm{C}, \mathrm{O}, \mathrm{H}$, and $\mathrm{Si}$ atoms are depicted in grey, red, white, and dark cyan color, respectively.

(a)

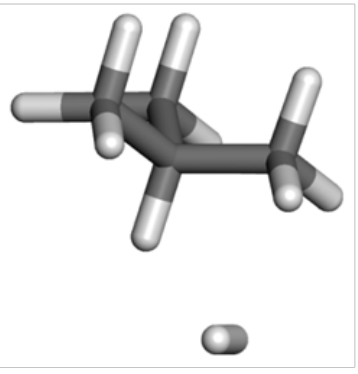

(b)

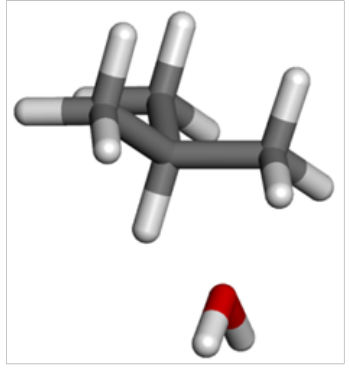

(c)

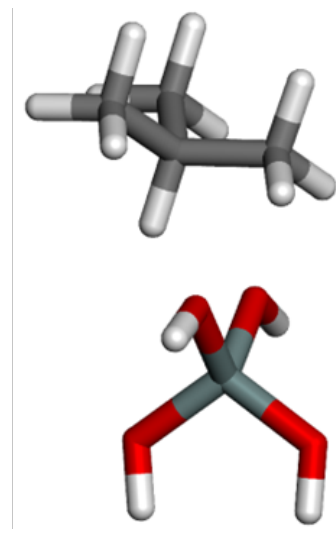

Figure S4: Definition of the reference set used for the generation of the DFT/CC correction functions: (a) iso- $\mathrm{C}_{4} \mathrm{H}_{10} \cdots \mathrm{H}_{2}\left(\mathrm{C}_{\mathrm{s}}\right)$, (b) iso- $\mathrm{C}_{4} \mathrm{H}_{10} \cdots \mathrm{H}_{2} \mathrm{O}\left(\mathrm{C}_{\mathrm{s}}\right)$, and (c) iso- $\mathrm{C}_{4} \mathrm{H}_{10} \cdots \mathrm{Si}(\mathrm{OH})_{4}\left(\mathrm{C}_{\mathrm{s}}\right)$. The $\mathrm{C}, \mathrm{O}, \mathrm{H}$, and $\mathrm{Si}$ atoms are depicted in grey, red, white, and dark cyan color, respectively. 
(a)

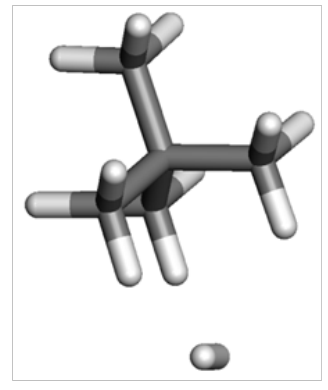

(b)

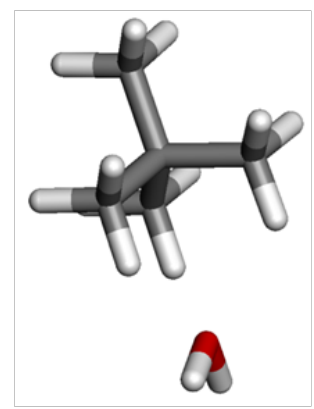

(c)

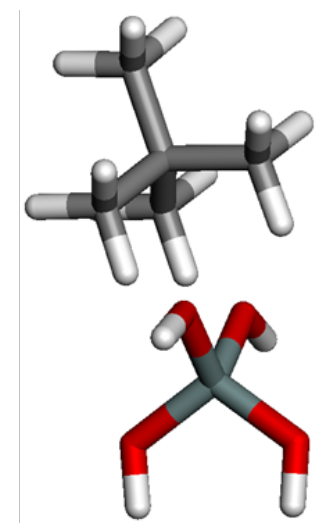

Figure S5: Definition of the reference set used for the generation of the DFT/CC correction functions: (a) neo- $\mathrm{C}_{5} \mathrm{H}_{12} \cdots \mathrm{H}_{2}\left(\mathrm{C}_{\mathrm{s}}\right)$, (b) neo- $\mathrm{C}_{5} \mathrm{H}_{12} \cdots \mathrm{H}_{2} \mathrm{O}\left(\mathrm{C}_{\mathrm{s}}\right)$, and (c) neo- $\mathrm{C}_{5} \mathrm{H}_{12} \cdots \mathrm{Si}(\mathrm{OH})_{4}\left(\mathrm{C}_{\mathrm{s}}\right)$. The $\mathrm{C}, \mathrm{O}, \mathrm{H}$, and $\mathrm{Si}$ atoms are depicted in grey, red, white, and dark cyan color, respectively.

(a)

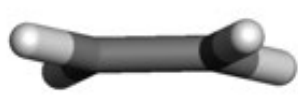

(a)

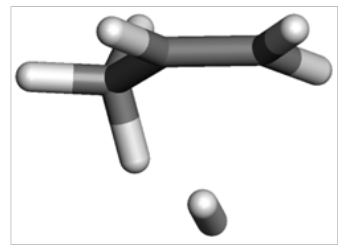

(b)
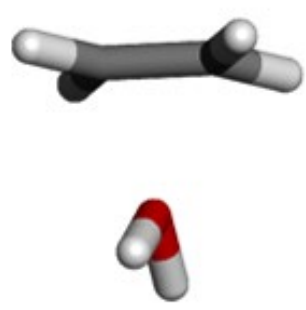

(c)

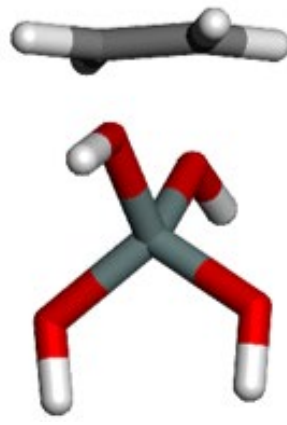

Figure S6: Definition of the reference set used for the generation of the DFT/CC correction functions: (a) $\mathrm{C}_{2} \mathrm{H}_{4} \cdots \mathrm{H}_{2}\left(\mathrm{C}_{2 \mathrm{v}}\right)$, (b) $\mathrm{C}_{2} \mathrm{H}_{4} \cdots \mathrm{H}_{2} \mathrm{O}\left(\mathrm{C}_{2 \mathrm{v}}\right)$, and (c) $\mathrm{C}_{2} \mathrm{H}_{4} \cdots \mathrm{Si}(\mathrm{OH})_{4}\left(\mathrm{C}_{2 \mathrm{v}}\right)$. The $\mathrm{C}, \mathrm{O}, \mathrm{H}$, and $\mathrm{Si}$ atoms are depicted in grey, red, white, and dark cyan color, respectively.

Fire S7: Definition of the reference set used for the generation of the DFT/CC correction functions: (a) $\mathrm{C}_{3} \mathrm{H}_{6} \cdots \mathrm{H}_{2}$, (b) $\mathrm{C}_{3} \mathrm{H}_{6} \cdots \mathrm{H}_{2} \mathrm{O}$, and (c) $\mathrm{C}_{3} \mathrm{H}_{6} \cdots \mathrm{Si}(\mathrm{OH})_{4}$. The $\mathrm{C}, \mathrm{O}, \mathrm{H}$, and $\mathrm{Si}$ atoms are depicted in grey, red, white, and dark cyan color, respectively. 
(a)

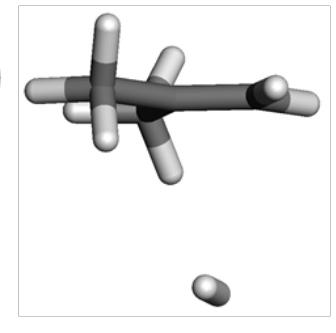

(b)

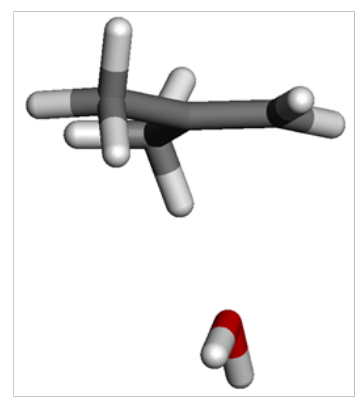

(c)
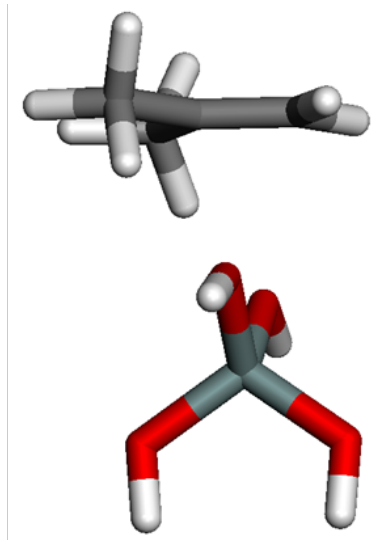

Figure S8: Definition of the reference set used for the generation of the DFT/CC correction functions: (a) iso- $\mathrm{C}_{4} \mathrm{H}_{8} \cdots \mathrm{H}_{2}\left(\mathrm{C}_{\mathrm{s}}\right)$, (b) iso- $\mathrm{C}_{4} \mathrm{H}_{8} \cdots \mathrm{H}_{2} \mathrm{O}\left(\mathrm{C}_{\mathrm{s}}\right)$, and (c) iso- $\mathrm{C}_{4} \mathrm{H}_{8} \cdots \mathrm{Si}(\mathrm{OH})_{4}\left(\mathrm{C}_{\mathrm{s}}\right)$. The $\mathrm{C}, \mathrm{O}, \mathrm{H}$, and $\mathrm{Si}$ atoms are depicted in grey, red, white, and dark cyan color, respectively.

Here, all calculations to get $\mathrm{PBE}$ and $\operatorname{CCSD}(\mathrm{T}) / \mathrm{CBS}$ energies were performed in the GAUSSIAN 09 program using the standard Dunning's augmented correlation-consistent valence- $X-\zeta$ basis sets with polarization functions, with $X=$ double, triple, quadruple, or quintuple basis sets (designated as AVDZ, AVTZ, AVQZ, and AV5Z, respectively). ${ }^{3-7}$ All calculated interaction energies were corrected for the basis-set superposition error using the counterpoise correction method of Boys and Bernardi. ${ }^{8}$ Before these calculations, the geometries of $\mathrm{H}_{2}, \mathrm{H}_{2} \mathrm{O}$, $\mathrm{C}_{2} \mathrm{H}_{6}$, and $\mathrm{C}_{2} \mathrm{H}_{4}$ monomers were optimized at the CCSD(T)/AVQZ level of theory and the geometries of $\mathrm{Si}(\mathrm{OH})_{4}, \mathrm{C}_{3} \mathrm{H}_{8}$, iso- $\mathrm{C}_{4} \mathrm{H}_{10}, \mathrm{C}_{3} \mathrm{H}_{6}$, and iso- $\mathrm{C}_{4} \mathrm{H}_{8}$ monomers were optimized at the MP2/AVQZ level.

The estimated CCSD(T)/CBS energy for $\mathrm{C}_{\mathrm{x}} \mathrm{H}_{\mathrm{y}} \cdots \mathrm{H}_{2}$ and $\mathrm{C}_{\mathrm{x}} \mathrm{H}_{\mathrm{y}} \cdots \mathrm{H}_{2} \mathrm{O}$ complexes can be obtained using the formula, $E_{C B S}^{C C S D(T)}=E_{A V T Z}^{C C S D(T)}-E_{A V T Z}^{M P 2}+E_{C B S}^{M P 2-H F}+E_{A V 5 Z}^{H F}$. The estimated $\operatorname{CCSD}(\mathrm{T}) / \mathrm{CBS}$ energy for $\mathrm{C}_{\mathrm{x}} \mathrm{H}_{\mathrm{y}} \cdots \mathrm{Si}(\mathrm{OH})_{4}$ complex can be obtained using the formula, $E_{C B S}^{C C S D(T)}=E_{A V D Z}^{C C S D(T)}-E_{A V D Z}^{M P 2}+E_{C B S}^{M P 2-H F}+E_{A V 5 Z}^{H F}$. The CBS extrapolation $E_{C B S}^{M P 2-H F}$ is calculated by the 
two point extrapolation formula, $E_{X}^{M P 2-H F}=E_{C B S}^{M P 2-H F}+A \cdot X^{-3},{ }^{9}$, where $E_{X}^{M P 2-H F}$ is the correlation energy obtained with the basis set with cardinal number $X(X=3,4)$.

The correction curve is represented by means of the RP-RKHS functional form, ${ }^{10,11}$

$$
\varepsilon_{i j}\left(R_{i j}\right)=\sum_{k} \alpha_{k} q\left(R_{i j}^{2}, R_{k}^{2}\right)
$$

with a selected grid dependent kernel function $q^{3,4}$ :

$$
q\left(R_{i j}^{2}, R_{k}^{2}\right)=\frac{1}{3 R_{>}^{6}}-\frac{R_{<}^{2}}{5 R_{>}^{8}}
$$

where $R_{i j}$ are intermolecular atomic distances between $\mathrm{i}$ and $\mathrm{j}, R_{k}$ are yet unspecified grid points, $R>=\max \left(R_{i j}, R_{k}\right), R_{<}=\min \left(R_{i j}, R_{k}\right)$, and $\alpha_{k}$ are interpolation coefficients. The interpolation coefficients $\alpha_{k}$ and hence $\varepsilon_{\mathrm{ij}}$ were calculated as follows: for a fixed monomer-monomer orientation, we calculated the correction energies $\Delta E(\mathrm{R})$ on a selected grid in $\mathrm{R}$. The corresponding RP-RKHS functional forms of $\varepsilon_{\mathrm{ij}}$ (Eq. (S2)) along with calculated correction energies $\Delta E$ were substituted into the pairwise additive approximation (Eq. (S1)). This led to a system of linear equations for $\alpha_{k}$, which were solved numerically using the Tikhonov regularization algorithm. ${ }^{12,13}$ Once $\alpha_{\mathrm{k}}$ are known, the $\varepsilon_{\mathrm{ij}}$ can be easily obtained using equation (S2). The numerical values of the correction functions $\varepsilon$ (in $\mathrm{kJ} / \mathrm{mol}$ ) and interpolation coefficients $\alpha$ as a function of atom-atom distances $R$ (in $\AA$ ) are reported in Excel tables in the attached data.

The resulting correction functions can be used in periodic systems for dispersion corrections to improve the DFT description of large systems that can only be computed at the DFT level. For example, the interaction between alkanes/akenes and silica zeolite could, in principle, be corrected using correction functions obtained for the abovementioned reference sets. 
In this work, we employ the DFT/CC method for developing a force field that describes interactions between these hydrocarbons and silica zeolite. 
S2. Additional adsorption isotherms validation

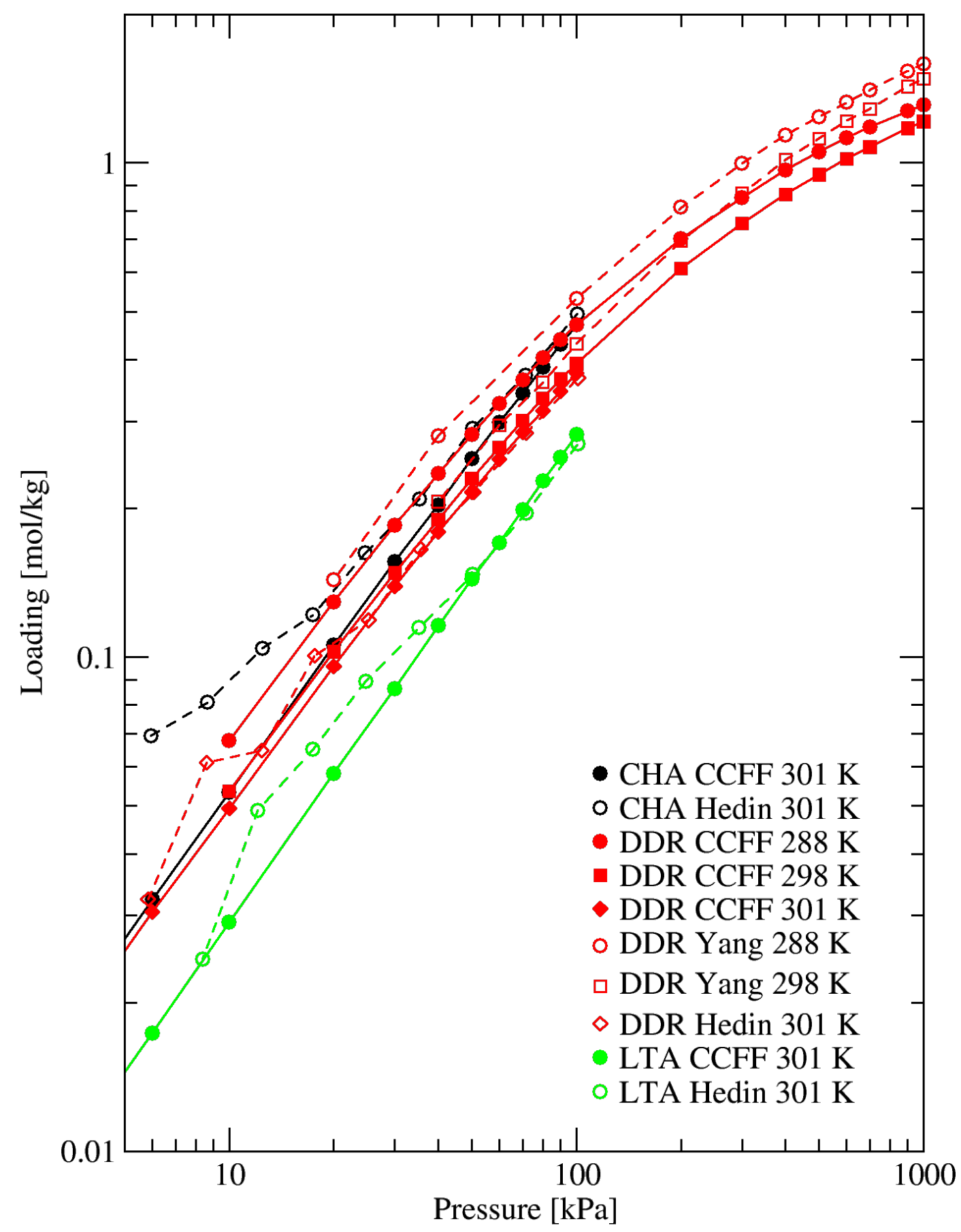

Figure S9: Simulated (filled) and experimental (open) methane adsorption isotherms are shown for $\mathrm{CHA}^{14}$ (black), DDR ${ }^{15}$ (red) and $\mathrm{LTA}^{14}$ (green). 


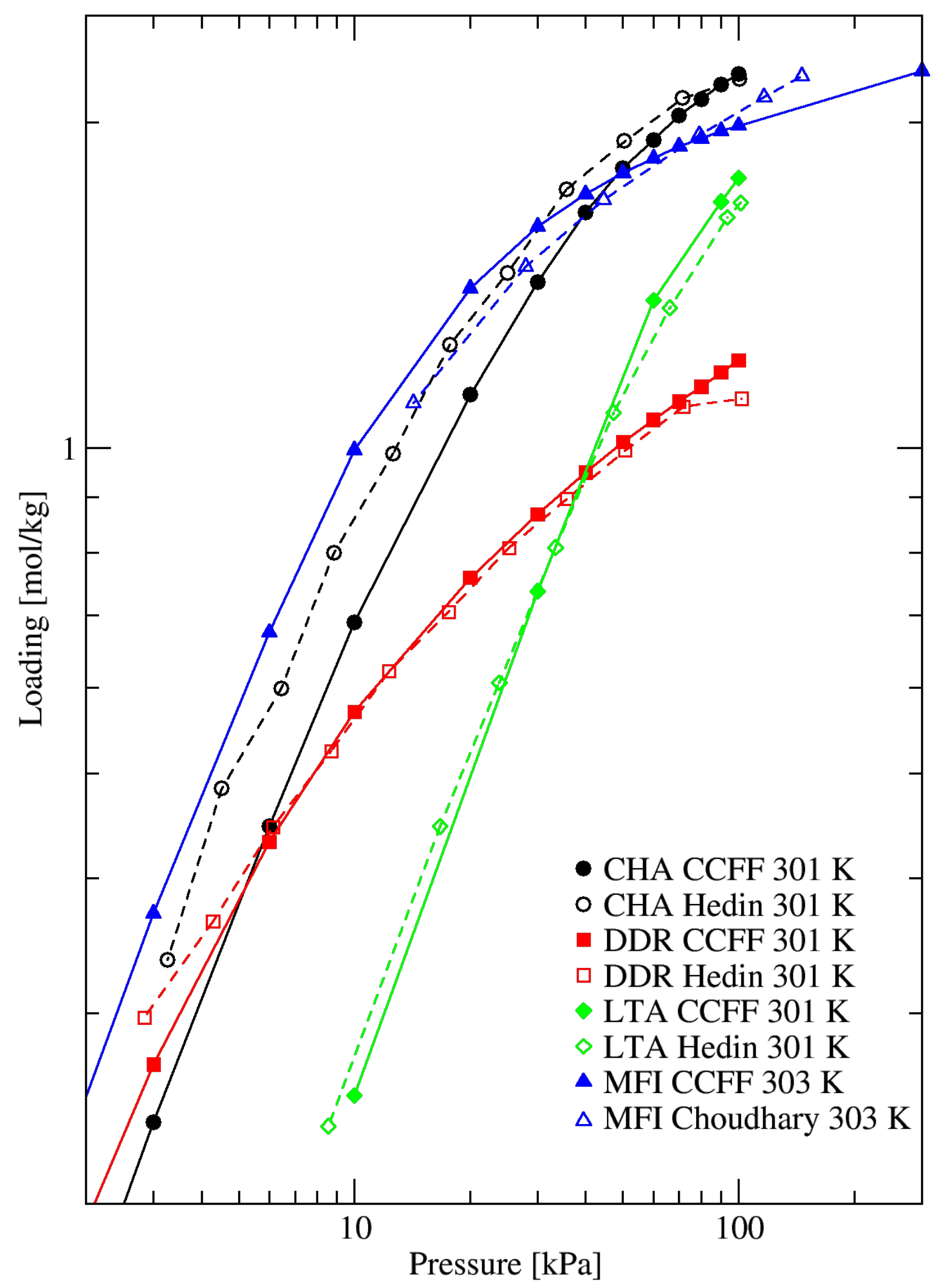

Figure S10: Simulated (filled) and experimental (open) ethane adsorption isotherms are shown for $\mathrm{CHA}^{14}$ (black), $\mathrm{DDR}^{14}$ (red), $\mathrm{LTA}^{14}$ (green) and $\mathrm{MFI}^{16}$ (blue). 


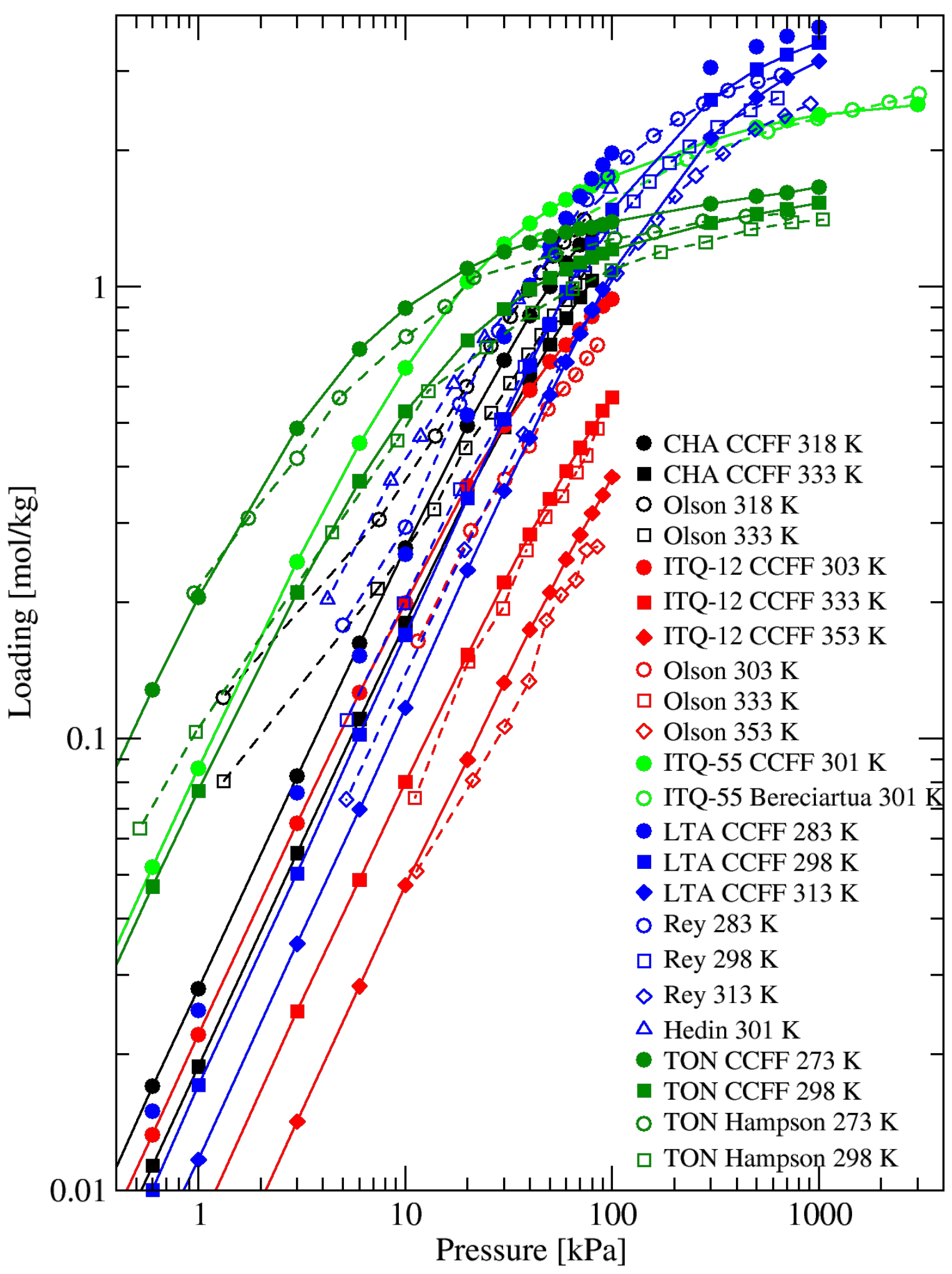

Figure S11: Simulated (filled) and experimental (open) ethylene adsorption isotherms are shown for $\mathrm{CHA}^{17}$ (black), ITQ-12 $2^{17}$ (red), ITQ-55 ${ }^{18}$ (light green), LTA ${ }^{14,19}$ (blue), and TON ${ }^{20}$ (dark green) 


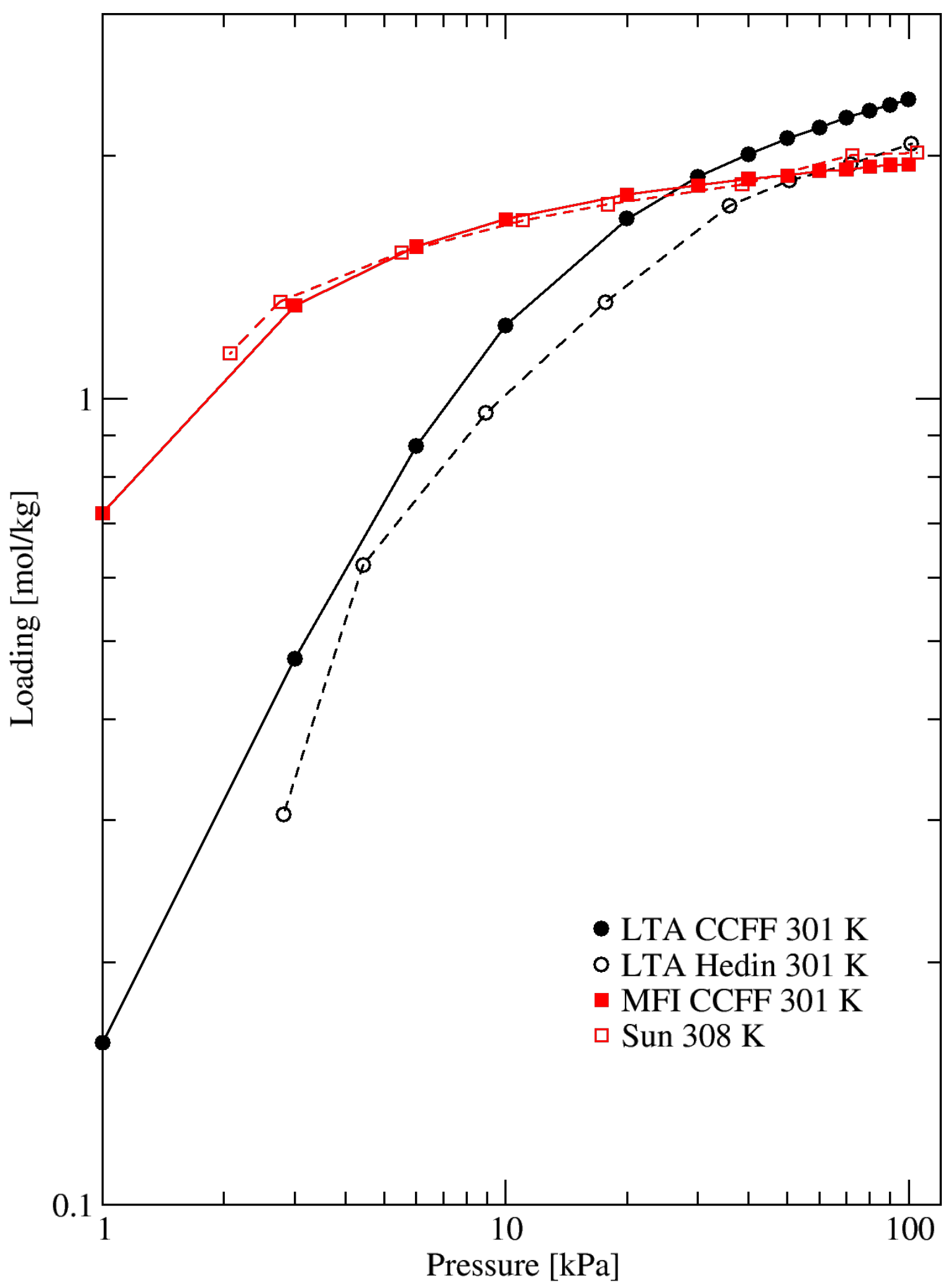

Figure S12: Simulated (filled) and experimental (open) propane adsorption isotherms are shown for LTA $^{14}$ (black), and MFI (red). 


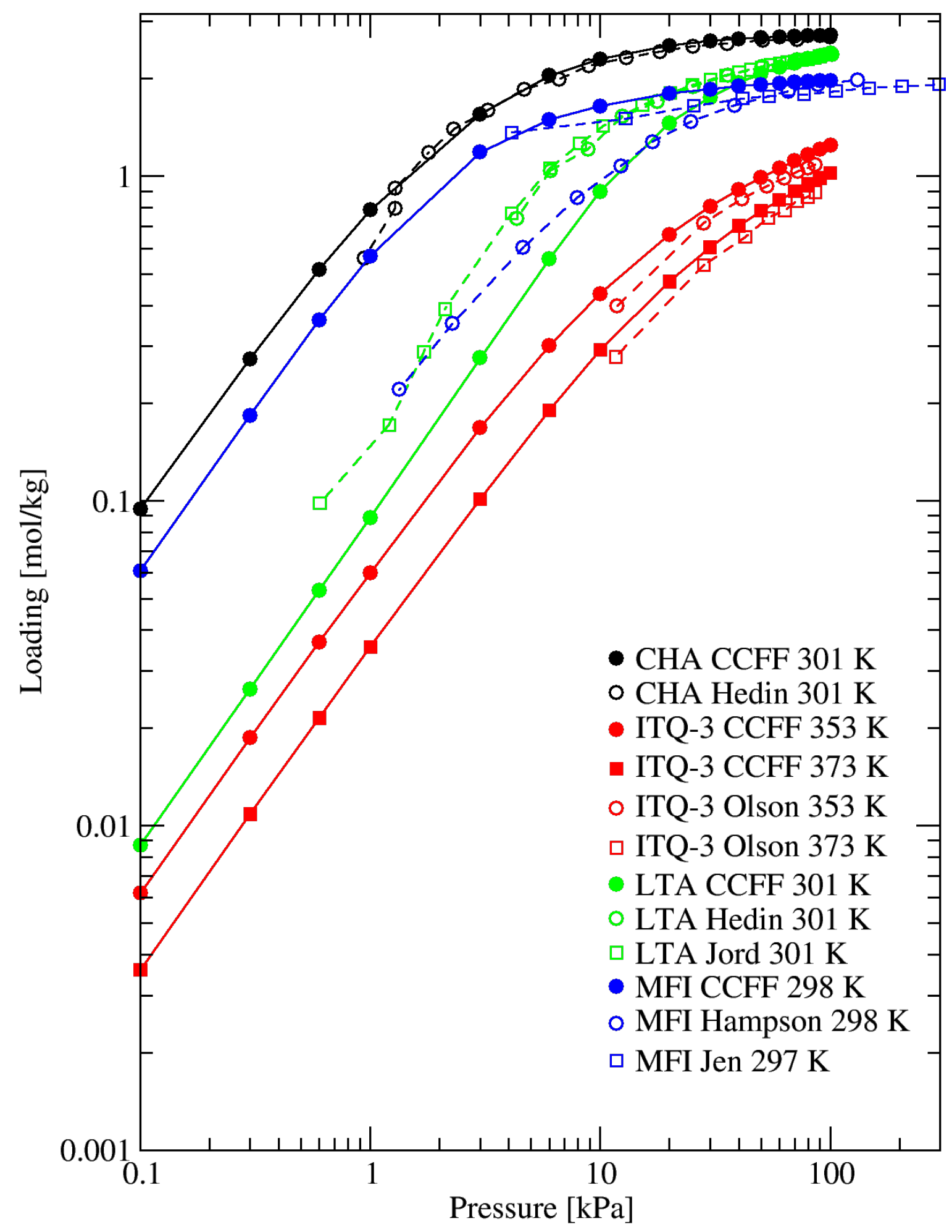

Figure S13: Simulated (filled) and experimental (open) propylene adsorption isotherms are shown for $\mathrm{CHA}^{14}$ (black), ITQ-3 ${ }^{17}$ (red), LTA $^{14}$ (green) and $\mathrm{MFI}^{20,21}$ (blue). 
S3. Literature force fields of methane and ethane in silica zeolites

Table S1: A list of parameters taken from the literature and this work that were used to predict $\mathrm{CH}_{4}$ adsorption isotherms and self-diffusivities in Figure 3 and Figure 7 respectively.

\begin{tabular}{|c|c|c|c|c|c|c|c|}
\hline \multicolumn{2}{|c|}{$\mathrm{CH}_{4}-\mathrm{O}$} & \multicolumn{2}{|c|}{$\mathrm{CH}_{4}-\mathrm{CH}_{4}$} & \multicolumn{2}{|c|}{$\mathrm{CH}_{4}-\mathrm{Si}$} & \multirow[t]{2}{*}{ Ref. } & \multirow[t]{2}{*}{ Code } \\
\hline$\sigma[\AA]$ & $\epsilon[\mathrm{K}]$ & $\sigma[\AA]$ & $\epsilon[\mathrm{K}]$ & $\sigma[\AA]$ & $\epsilon[\mathrm{K}]$ & & \\
\hline 3.510 & 200.334 & 4.482 & 221.000 & - & - & 22 & FF1 \\
\hline 3.140 & 180.410 & 3.817 & 148.176 & 2.140 & 34.879 & $23-25$ & FF2 \\
\hline 3.460 & 97.421 & 3.817 & 148.176 & 2.140 & 34.879 & $23,24,26$ & FF3 \\
\hline 3.140 & 97.421 & 3.817 & 148.176 & 2.140 & 34.879 & 27 & FF4 \\
\hline 3.214 & 133.263 & 3.730 & 147.936 & - & - & 28,29 & FF5 \\
\hline 3.694 & 90.794 & 3.730 & 147.936 & - & - & 30,31 & FF6 \\
\hline 3.370 & 118.415 & 3.740 & 149.920 & - & - & 32 & FF7 \\
\hline 3.600 & 96.459 & 3.730 & 148.056 & - & - & 33 & FF8 \\
\hline 3.370 & 75.772 & 3.440 & 221.303 & 3.750 & 135.909 & 30 & FF9 \\
\hline 3.080 & 141.000 & 3.882 & 137.000 & - & - & 34 & FF10 \\
\hline 3.515 & 88.570 & 3.730 & 148.000 & 3.015 & 57.061 & 35 & FF11 \\
\hline 3.470 & 115.000 & 3.720 & 158.500 & - & - & $36-38$ & FF12 \\
\hline 3.885 & 97.625 & 3.880 & 216.900 & - & - & 39 & FF13 \\
\hline 3.501 & 104.5 & 3.737 & 151.400 & - & - & 40 & FF14 \\
\hline 3.417 & 109.261 & 3.730 & 148.000 & - & - & This Work & CCFF \\
\hline
\end{tabular}

Table S2: A list of parameters taken from the literature and this work that were used to predict $\mathrm{C}_{2} \mathrm{H}_{6}$ adsorption isotherms and self-diffusivities in Figure S20.

\begin{tabular}{|c|c|c|c|c|c|c|c|c|}
\hline \multicolumn{2}{|c|}{$\mathrm{CH}_{3}-\mathrm{O}$} & \multicolumn{2}{c|}{$\mathrm{CH}_{3}-\mathrm{CH}_{3}$} & \multicolumn{2}{c|}{$\mathrm{CH}_{3}-\mathrm{Si}$} & lc-C & \multirow{2}{*}{ Ref. } & \multirow{2}{*}{ Code } \\
\cline { 1 - 6 }$\sigma[\AA]$ & $\epsilon[\mathrm{K}]$ & $\sigma[\AA ̊]$ & $\epsilon[\mathrm{K}]$ & $\sigma[\AA]$ & $\epsilon[\mathrm{K}]$ & {$[\AA]$} & & \\
\hline 3.775 & 184.740 & - & - & - & - & 1.54 & 23 & FF1 \\
\hline 3.364 & 83.800 & 3.923 & 72.000 & - & - & 1.53 & 31,41 & FF2 \\
\hline 3.790 & 72.270 & 3.775 & 104.167 & - & - & 1.40 & 42,43 & FF3 \\
\hline 3.600 & 79.982 & 3.770 & 98.143 & - & - & 1.53 & 33,44 & FF4 \\
\hline 3.525 & 72.069 & 3.750 & 98.000 & 3.025 & 46.433 & 1.54 & 35,45 & FF5 \\
\hline 3.480 & 93.000 & 3.760 & 108.000 & - & - & 1.54 & $19,36,37$ & FF6 \\
\hline 3.480 & 94.106 & 3.760 & 108.000 & - & - & 1.54 & 38 & FF7 \\
\hline 3.640 & 87.500 & 3.905 & 88.060 & - & - & 1.53 & 46 & FF8 \\
\hline 3.170 & 141.922 & 3.780 & 104.157 & 2.120 & 82.147 & 1.54 & 47 & FF9 \\
\hline 3.600 & 79.982 & 3.770 & 98.143 & - & - & 1.54 & 48 & FF10 \\
\hline $\mathbf{3 . 4 0 3}$ & $\mathbf{9 0 . 8 5 8}$ & $\mathbf{3 . 7 5 0}$ & $\mathbf{9 8 . 0 0 0}$ & - & - & $\mathbf{1 . 5 4}$ & This Work & CCFF \\
\hline
\end{tabular}




\section{S4. Heat of adsorption validation}

Grand Canonical Monte Carlo simulations were performed using the RASPA package. The electrostatic energies were calculated using the Ewald summation method with a precision of $10^{-}$

${ }^{6}$ and the charges from Table 1. Dispersion interactions were calculated using a cutoff of $12.0 \AA$ using periodic boundary conditions and the $\mathrm{CCFF}$ parameters from Table 1. $\mathrm{CO}_{2}-\mathrm{CO}_{2}$ interactions were described using the EPM2 force-field, $\mathrm{N}_{2}-\mathrm{N}_{2}$ interactions were described by the force field from Theodorou et al., $\mathrm{H}_{2} \mathrm{O}-\mathrm{H}_{2} \mathrm{O}$ interactions were described by the SPC/E force field, $\mathrm{O}_{2}-\mathrm{O}_{2}$ interactions were described by the TraPPE force field and hydrocarbon hydrocarbon interactions were described by the TraPPE United Atom force field. Adsorption isotherms were calculated using the Grand Canonical Monte Carlo simulations. Isosteric heats of adsorption, $\mathrm{Q}_{\text {st }}$ were obtained from GCMC simulations using

$$
Q_{s t}=R T-\frac{<N V>-<N><V>}{<N^{2}>-<N>^{2}}
$$

where $\mathrm{R}$ is the gas constant, $\mathrm{T}$ is the temperature, $\mathrm{N}$ is the number of molecules, $\mathrm{V}$ is the sum of interactions of all adsorbed molecules with both the zeolite and one another and $<>$ denotes the ensemble average. GCMC simulations were run with $5 * 10^{4}$ initialization cycles and thermodynamic properties were sampled after $10^{5}$ cycles. The standard deviations in calculated loadings, computed using block averages, were typically less than $1 \%$ of the loadings and always less than $5 \%$. 


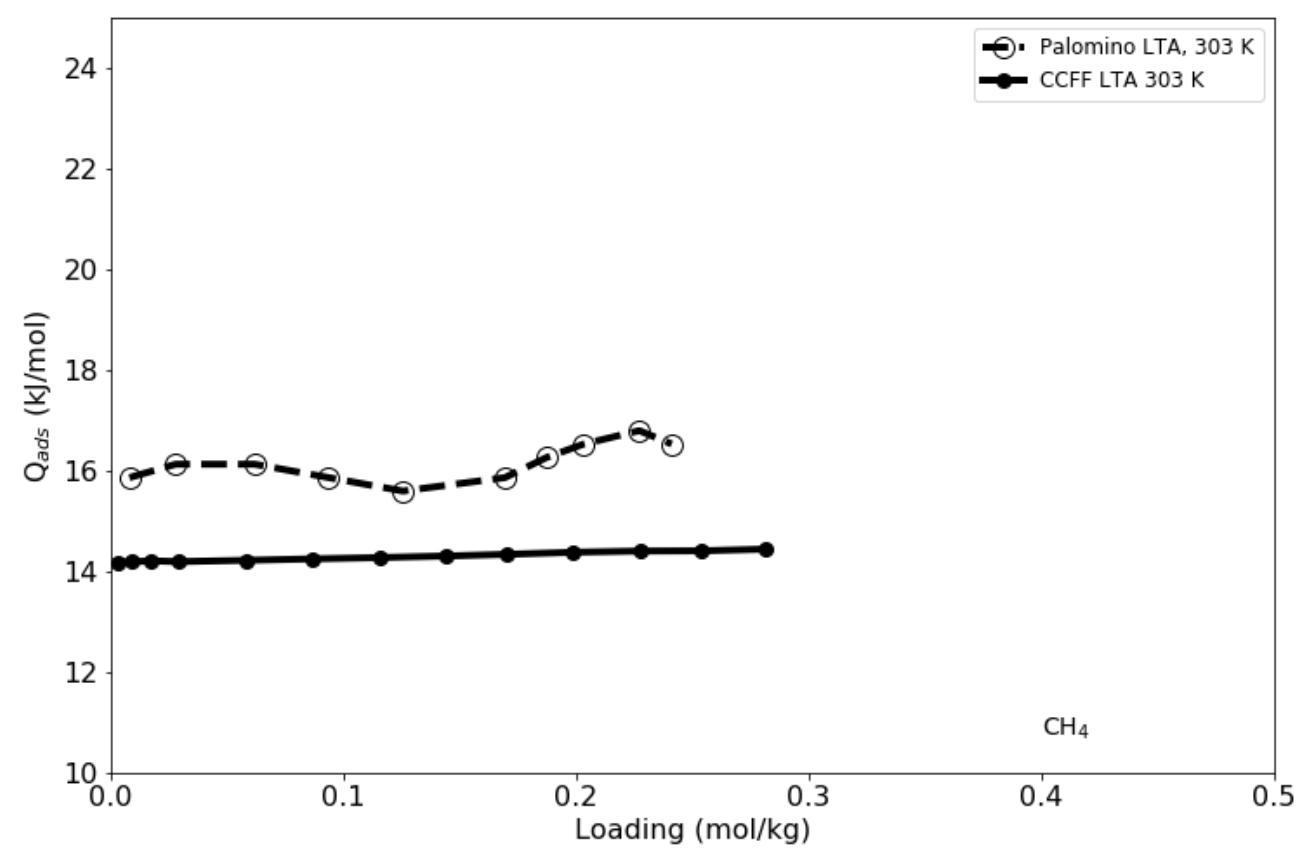

Figure S14: Simulated (filled) and experimental ${ }^{49}$ (open) methane heats of adsorption are shown for LTA.

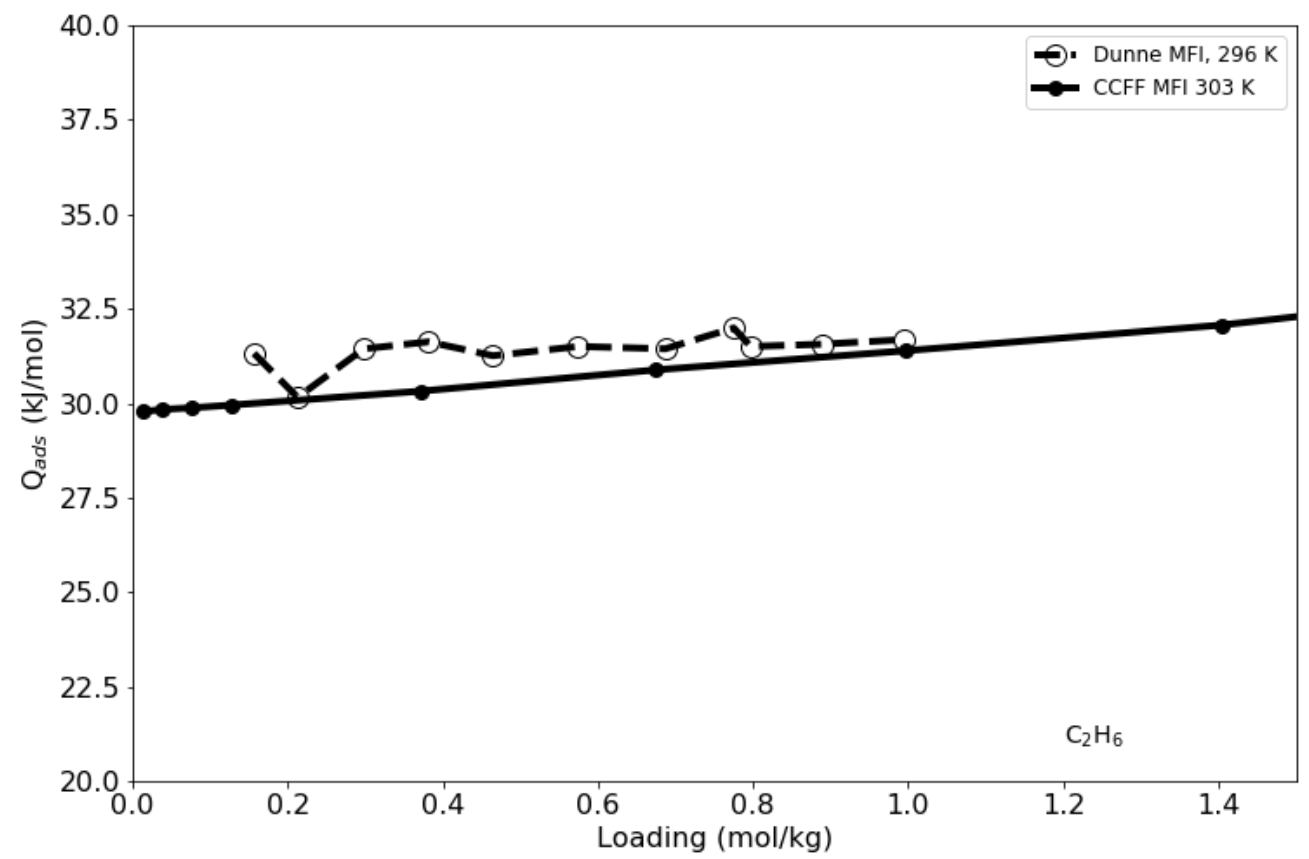

Figure S15: Simulated (filled) and experimental ${ }^{50}$ (open) ethane heats of adsorption are shown for MFI. 


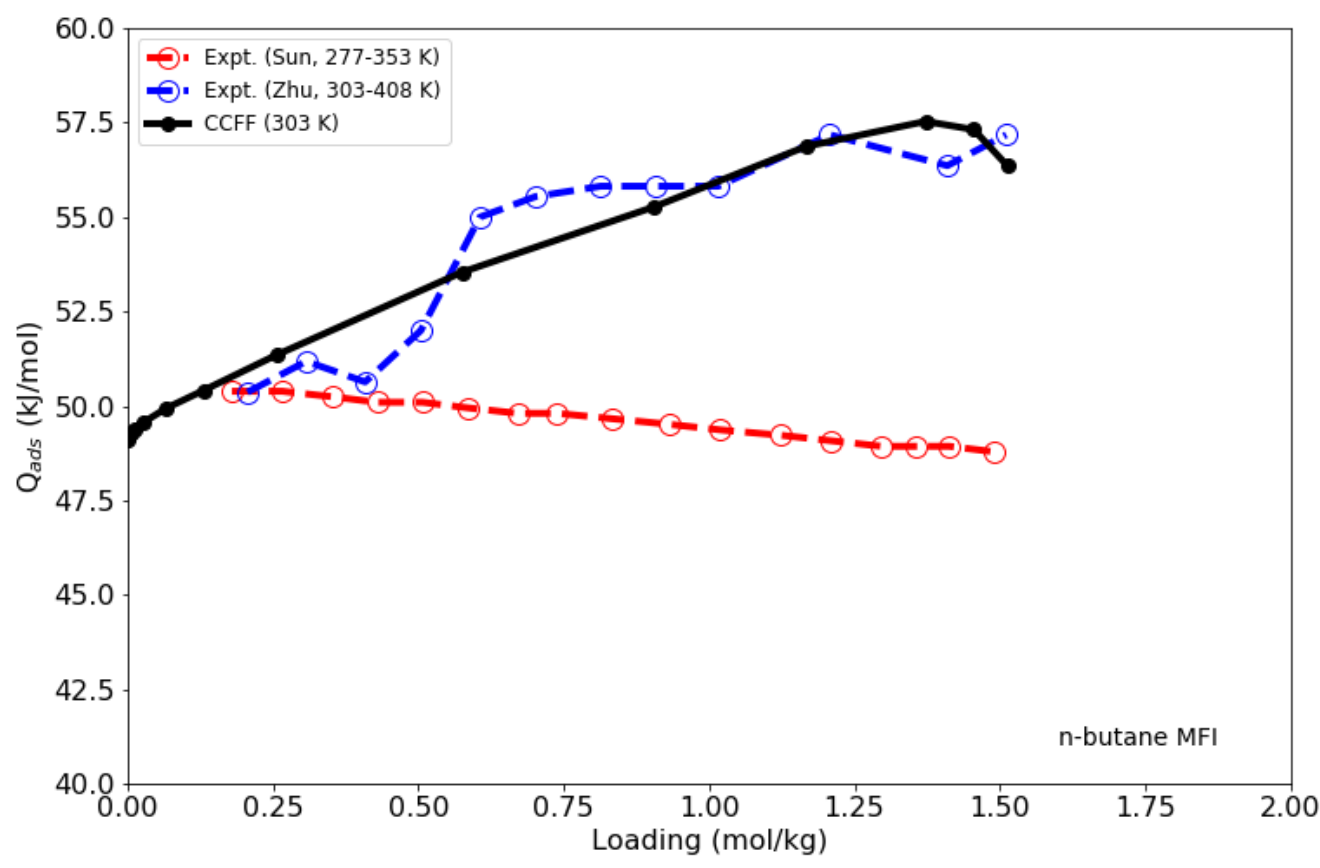

Figure S16: Simulated (black, filled) and experimental ${ }^{51,52}$ (open, red/blue) n-butane heats of adsorption are shown for MFI.

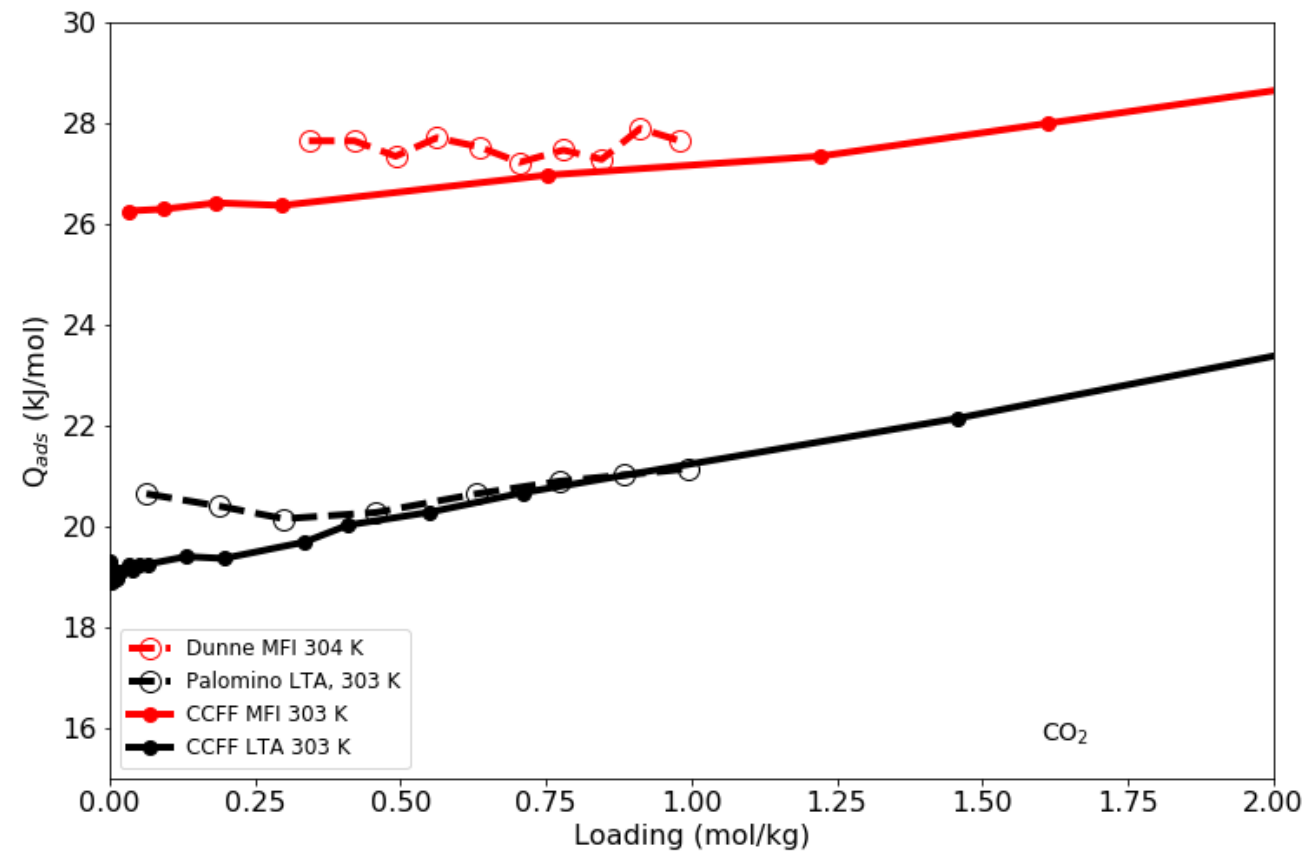

Figure S17: Simulated (filled) and experimental (open) $\mathrm{CO}_{2}$ heats of adsorption are shown for $\mathrm{MFI}^{50}$ (red) and $\mathrm{LTA}^{49}$ (black) 


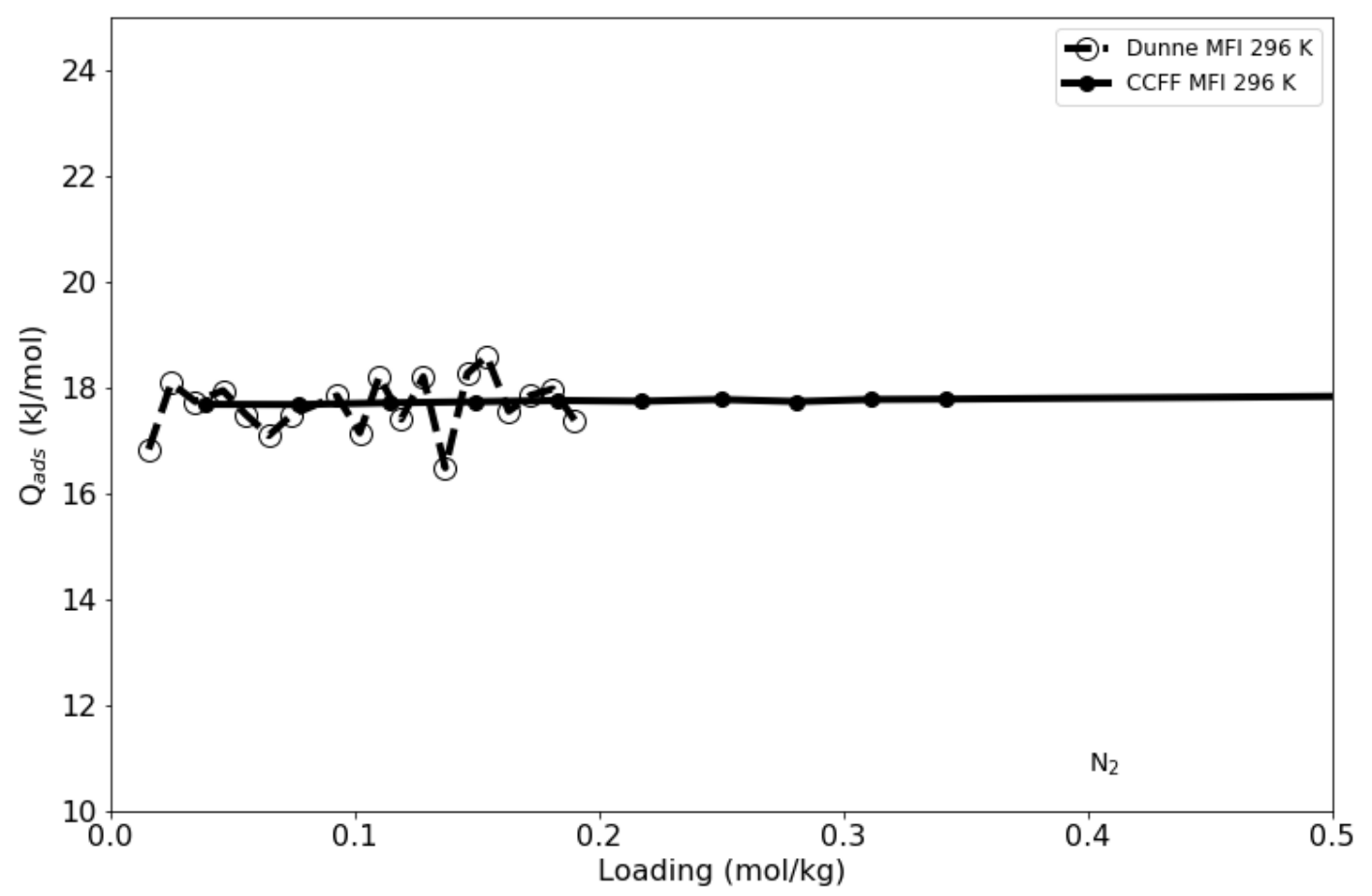

Figure S18: Simulated (filled) and experimental ${ }^{50}$ (open) $\mathrm{N}_{2}$ heats of adsorption are shown for MFI. 
S5. FF development for $\mathrm{H}_{2} \mathrm{O}$ in pure silica zeolites
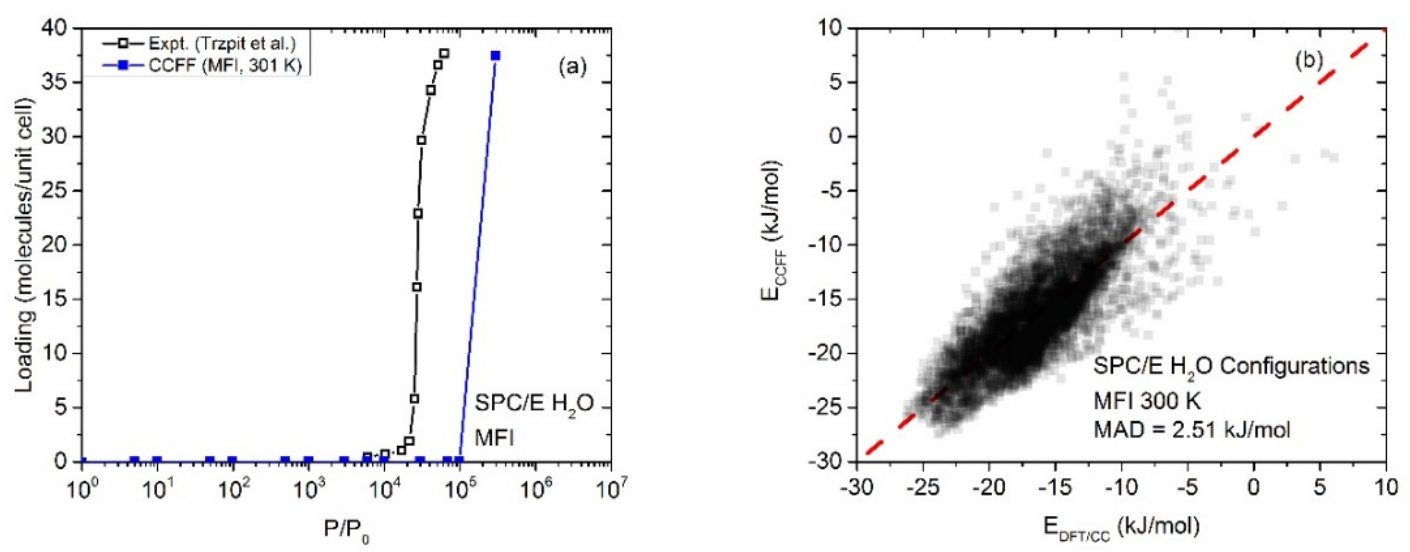

Figure S19: A comparison of simulated (blue) with experimental (black) adsorption isotherms (a) for CCFF for $\mathrm{H}_{2} \mathrm{O}$ and a comparison of DFT/CC energies and (b) CCFF energies for SPC/E water in pure-silica MFI. We observe reasonable agreement between (a) simulated and experimental adsorption isotherms and (b) good agreement between DFT/CC energies and CCFF energies (b).

Figure S.19(a) shows the experimental (black) and simulated (blue) $\mathrm{H}_{2} \mathrm{O}$ adsorption isotherms in pure-silica MFI. According to simulations by NIST, SPC/E water model predicts a saturation pressure of $1.017 \mathrm{kPa}^{53}$ at $300 \mathrm{~K}$, while the experimental saturation pressure $\left(\mathrm{P}_{0}\right)$ of water is $3.533 \mathrm{kPa}$ at $300 \mathrm{~K}^{54}$. In order to make a better comparison of experimental and simulated adsorption isotherms, both sets of pressure were divided by their corresponding value of $\mathrm{P}_{0}$. Our force field correctly predicts the order of magnitude of $\mathrm{P} / \mathrm{P}_{0}$ for water intrusion in pure-silica MFI. We did see that our FF slightly overpredicts the $\mathrm{H}_{2} \mathrm{O}$ intrusion pressure, however our simulations assumed a defect-free MFI, while it is very difficult to synthesize a completely defect-free zeolite. The presence of any $\mathrm{Si}(\mathrm{OH})$ groups could cause a decrease in intrusion pressure ${ }^{55}$. 
To demonstrate that our FF accurately predicted DFT/CC energies, we applied the constrained molecular dynamics methods from Figure 1 to the straight channels in MFI and calculated the energies using DFT/CC. The results are shown in Figure S.19(b), which demonstrate excellent agreement between our CCFF energies and DFT/CC energies with a mean absolute deviation (MAD) of $2.51 \mathrm{~kJ} / \mathrm{mol}$. 
S6. Additional diffusion validation

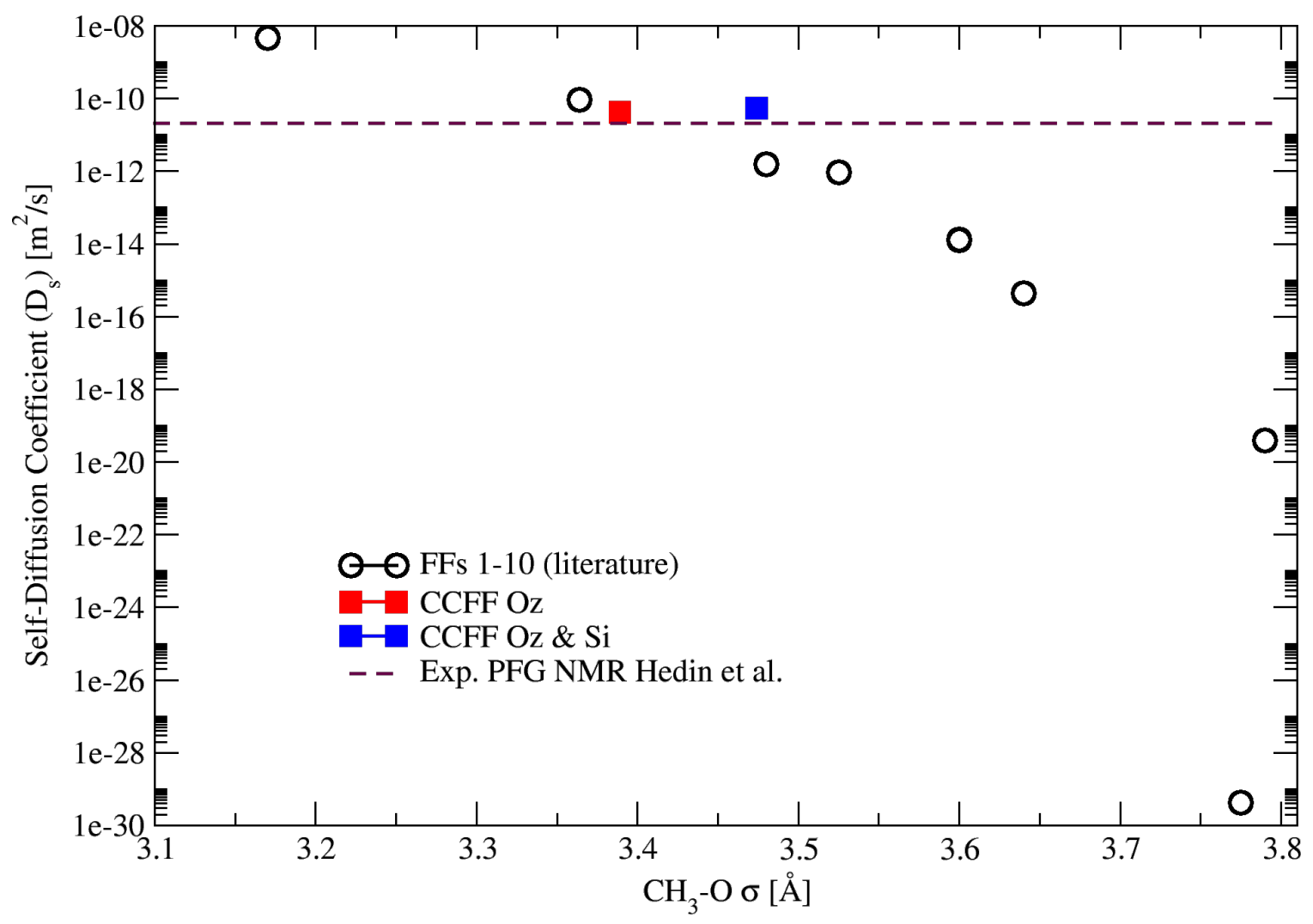

Figure S20: Self-diffusivities were computed for $\mathrm{C}_{2} \mathrm{H}_{6}$ in ITQ-29 using the CCFF (red, filled symbol) and the other FFs from the literature ${ }^{19,23,31,35-38,41-43,45-48}$ (open symbols). The results were compared to the experimental results of Hedin et al. ${ }^{14}$ (horizontal dashed line). 


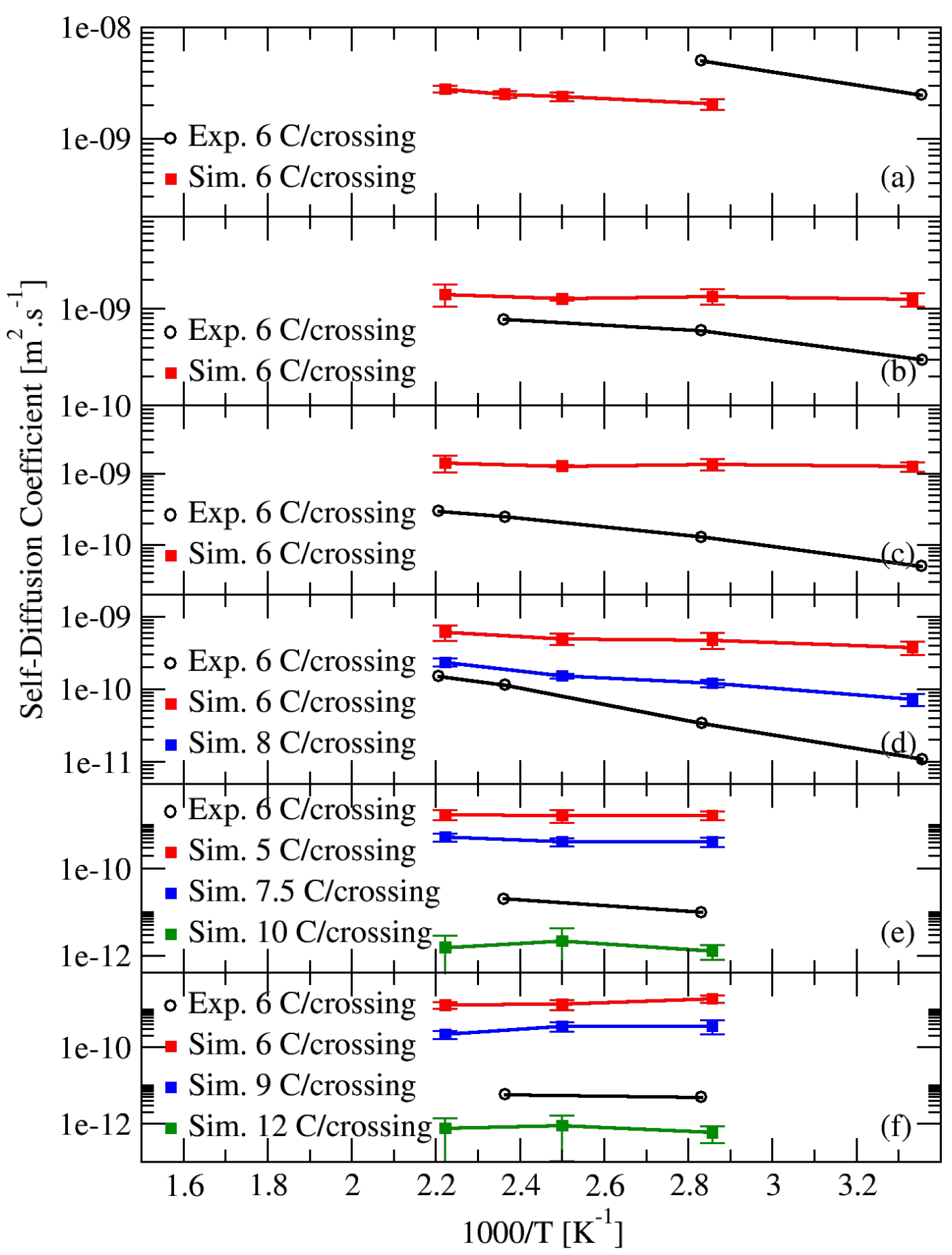

Figure S21: Temperature dependence of self-diffusivity of linear n-alkanes in silica MFI from molecular dynamics simulations and PFG NMR experiments: (a) ethane, (b) propane, (c) hexane, (d) octane, (e) decane, and (f) dodecane. The experimental results were taken from Jobic et al. ${ }^{56}$ 


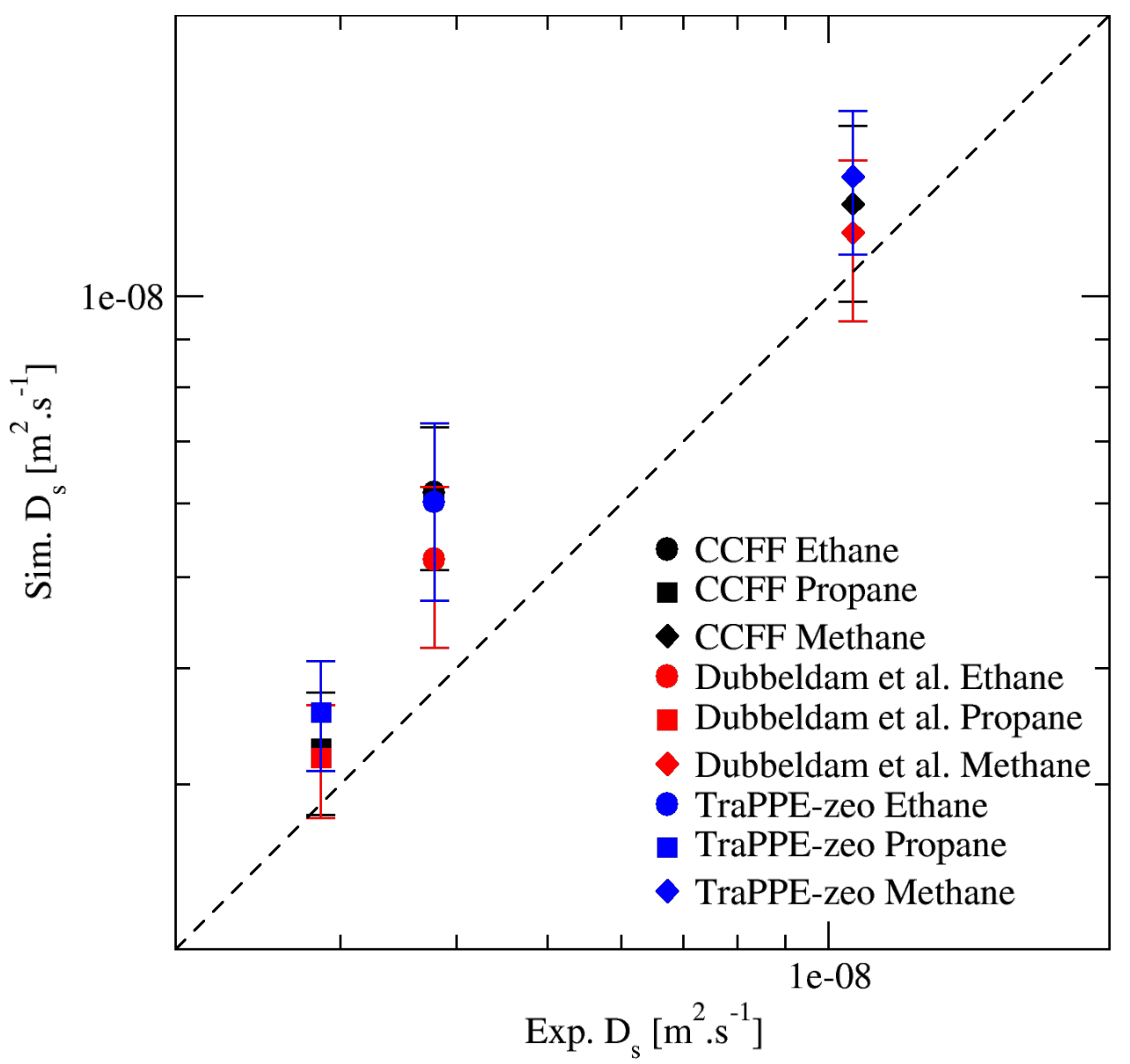

Figure S22: Self-diffusion coefficients of methane, ethane, and propane in silica MFI zeolite from molecular dynamics simulations using CCFF (black), Dubbeldam et al. ${ }^{37}$ (red), and TraPPE-zeo ${ }^{35}$ (blue). PFG NMR experimental data are from Kärger et al. ${ }^{57}$. 


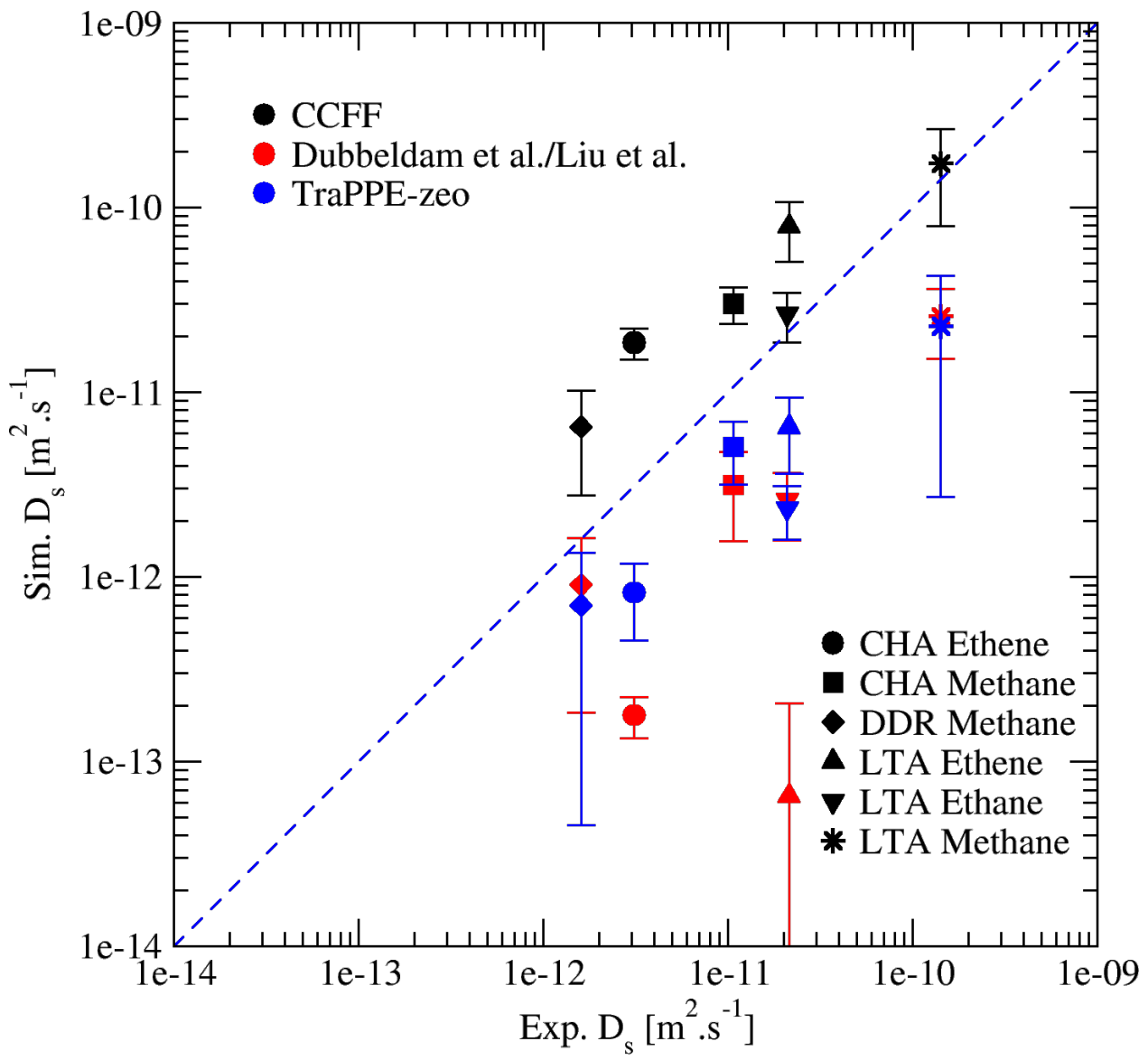

Figure S23: Self-diffusion coefficients of methane, ethane, and ethene in silica LTA, CHA, and DDR zeolites from molecular dynamics simulations using CCFF (black), Dubbeldam et al. ${ }^{37} / \mathrm{Liu}$ et al. ${ }^{19}$ (red), and TraPPE-zeo ${ }^{35}$ (blue). PFG NMR experimental data are from Hedin et al. ${ }^{14}$. 


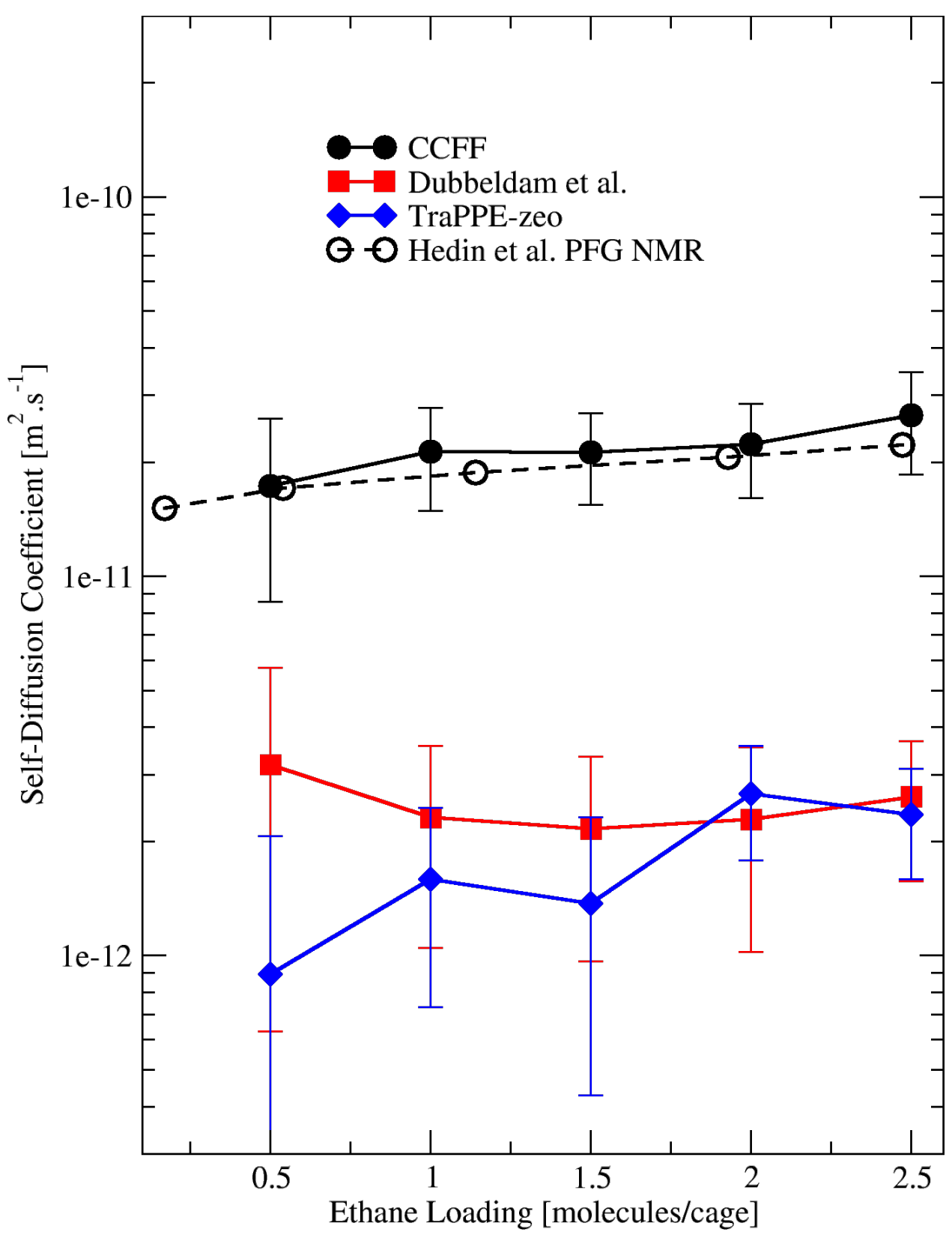

Figure S24: Loading dependence of self-diffusivity of ethane in silica LTA zeolite from molecular dynamics simulations using CCFF (filled black symbols), Dubbeldam et al. ${ }^{37}$ (filled red symbols), and TraPPE-zeo ${ }^{35}$ (filled blue symbols). PFG NMR experimental data (open black symbols) are from Hedin et al. ${ }^{14}$. 
The quality of our predictions of diffusion using CCFF is compared to some forcefields widely used in the literature for computing adsorption properties of hydrocarbons and small molecules in silica zeolites. The accuracy of forcefields from Dubbeldam et al. ${ }^{37}$ and Bai et al. ${ }^{35}$ (known as TraPPE-zeo) in predicting self-diffusivity of small hydrocarbons in medium-pore zeolites is very comparable to CCFF as shown in Figure S22 for methane, ethane, and propane in MFI zeolite. For small-pore zeolites, the predictions based on the forcefield developed Dubbeldam et al. ${ }^{37}$ for alkanes and later extended to alkenes by Liu et al. ${ }^{19}$ are less accurate compared to predictions obtained using CCFF and TraPPE-zeo ${ }^{35}$ as shown in Figure S23 for small hydrocarbons in LTA, CHA, and DDR. Despite the good accuracy and transferability of TraPPE-zeo forcefield as illustrated in Figures S22 and S23, CCFF helped improve theoretical predictions of diffusion as shown in Figure S24 for the loading dependence of self-diffusivity of ethane in LTA zeolite. 
References

1. Bludsky, O.; Rubes, M.; Soldan, P.; Nachtigall, P., Investigation of the benzene-dimer potential energy surface: DFT/CCSD(T) correction scheme. J Chem Phys 2008, 128 (11), 114102.

2. Fang, H. J.; Awati, R.; Boulfelfel, S. E.; Ravikovitch, P. I.; Sholl, D. S., FirstPrinciples-Derived Force Fields for $\mathrm{CH}_{4}$ Adsorption and Diffusion in Siliceous Zeolites. $J$ Phys Chem C 2018, 122 (24), 12880-12891.

3. Bludský, O.; Rubeš, M.; Soldán, P.; Nachtigall, P., Investigation of the benzene-dimer potential energy surface: DFT/CCSD(T) correction scheme. The Journal of Chemical Physics 2008, 128 (11), 114102 .

4. Pulido, A.; Delgado, M. R.; Bludsky, O.; Rubes, M.; Nachtigall, P.; Arean, C. O., Combined DFT/CC and IR spectroscopic studies on carbon dioxide adsorption on the zeolite HFER. Energ Environ Sci 2009, 2 (11), 1187-1195.

5. Chen, L.; Grajciar, L.; Nachtigall, P.; Düren, T., Accurate Prediction of Methane Adsorption in a Metal-Organic Framework with Unsaturated Metal Sites by Direct Implementation of an ab Initio Derived Potential Energy Surface in GCMC Simulation. The Journal of Physical Chemistry C 2011, 115 (46), 23074-23080.

6. Grajciar, L.; Bludský, O.; Nachtigall, P., Water Adsorption on Coordinatively Unsaturated Sites in CuBTC MOF. The Journal of Physical Chemistry Letters 2010, 1 (23), 3354-3359.

7. Rubeš, M.; Wiersum, A. D.; Llewellyn, P. L.; Grajciar, L.; Bludský, O.; Nachtigall, P., Adsorption of Propane and Propylene on CuBTC Metal-Organic Framework: Combined Theoretical and Experimental Investigation. The Journal of Physical Chemistry C 2013, 117 (21), 11159-11167.

8. Boys, S. F.; Bernardi, F., The calculation of small molecular interactions by the differences of separate total energies. Some procedures with reduced errors. Molecular Physics 1970, 19 (4), 553-566.

9. Halkier, A.; Helgaker, T.; Jorgensen, P.; Klopper, W.; Koch, H.; Olsen, J.; Wilson, A. K., Basis-set convergence in correlated calculations on $\mathrm{Ne}, \mathrm{N}_{2}$, and $\mathrm{H}_{2} \mathrm{O}$. Chem Phys Lett 1998, $286(3-4), 243-252$.

10. Ho, T. S.; Rabitz, H., A general method for constructing multidimensional molecular potential energy surfaces from ab initio calculations. J Chem Phys 1996, 104 (7), 2584-2597.

11. Soldan, P.; Hutson, J. M., On the long-range and short-range behavior of potentials from reproducing kernel Hilbert space interpolation. J Chem Phys 2000, 112 (9), 4415-4416.

12. Tikhonov, A.; Arsenin, V., Solutions of Ill-Posed Problems, translation ed. by F. John (Winston/Wiley, Washington DC/New York 1977) 1977, 10.

13. Tikhonov, A. N.; Goncharsky, A.; Stepanov, V.; Yagola, A. G., Numerical methods for the solution of ill-posed problems. Springer Science \& Business Media: 2013; Vol. 328.

14. Hedin, N.; DeMartin, G. J.; Roth, W. J.; Strohmaier, K. G.; Reyes, S. C., PFG NMR self-diffusion of small hydrocarbons in high silica DDR, CHA and LTA structures. Microporous and Mesoporous Materials 2008, 109 (1-3), 327-334.

15. Yang, J.; Li, J.; Wang, W.; Li, L.; Li, J., Adsorption of $\mathrm{CO}_{2}, \mathrm{CH}_{4}$, and $\mathrm{N}_{2}$ on 8-, 10-, and 12-membered ring hydrophobic microporous high-silica zeolites: DDR, silicalite-1, and beta. Industrial \& Engineering Chemistry Research 2013, 52 (50), 17856-17864. 
16. Choudhary, V. R.; Mayadevi, S., Adsorption of methane, ethane, ethylene, and carbon dioxide on silicalite-1. Zeolites 1996, 17 (5-6), 501-507.

17. Olson, D. H.; Camblor, M. A.; Villaescusa, L. A.; Kuehl, G. H., Light hydrocarbon sorption properties of pure silica Si-CHA and ITQ-3 and high silica ZSM-58. Microporous and mesoporous materials 2004, 67 (1), 27-33.

18. Bereciartua, P. J.; Cantín, Á.; Corma, A.; Jordá, J. L.; Palomino, M.; Rey, F.; Valencia, S.; Corcoran, E. W.; Kortunov, P.; Ravikovitch, P. I., Control of zeolite framework flexibility and pore topology for separation of ethane and ethylene. Science 2017, 358 (6366), 1068-1071.

19. Liu, B.; Smit, B.; Rey, F.; Valencia, S.; Calero, S., A new united atom force field for adsorption of alkenes in zeolites. The Journal of Physical Chemistry C 2008, 112 (7), 2492-2498.

20. Hampson, J.; Rees, L., Fundamentals of Adsorption. Kodansha/Elsevier: Tokoy/Amserdam: 1993; pp 259-266.

21. Jen, H.; Otto, K., Chemisorption of alkenes on copper-exchanged ZSM-5 zeolite. Catalysis letters 1994, 26 (1-2), 217-225.

22. Yashonath, S.; Bandyopadhyay, S., Surprising Diffusion Behavior in the Restricted Regions of Silicalite. Chem Phys Lett 1994, 228 (1-3), 284-288.

23. Haberlandt, R., Transport processes in porous media: diffusion in zeolites. Thin Solid Films 1998, 330 (1), 34-45.

24. Fritzsche, S.; Haberlandt, R.; Karger, J.; Pfeifer, H.; Heinzinger, K., On the diffusion mechanism of methane in a cation-free zeolite of type ZK4. Chem Phys 1993, 174 (2), 229-236.

25. Bezus, A. G.; Kiselev, A. V.; Lopatkin, A. A.; Du, P. Q., Molecular statistical calculation of the thermodynamic adsorption characteristics of zeolites using the atom-atom approximation. Part 1.-Adsorption of methane by zeolite NaX. Journal of the Chemical Society, Faraday Transactions 2: Molecular and Chemical Physics 1978, 74, 367-379.

26. Ruthven, D. M.; Derrah, R. I., Transition-state theory of zeolitic diffusion. Diffusion of $\mathrm{CH}_{4}$ and $\mathrm{CF}_{4}$ in $5 \mathrm{~A}$ zeolite. J Chem Soc Farad T 1 1972, 68 (12), 2332-\&.

27. Fritzsche, S.; Haberlandt, R.; Wolfsberg, M., Equilibration of the kinetic energy in small zeolite cavities - The thermalization effect of lattice vibrations and of mutual interaction in the diffusion of methane in a cation-free LTA zeolite. Chem Phys 2000, 253 (2-3), 283-294.

28. Jost, S.; Fritzsche, S.; Haberlandt, R., An MD study on the diffusion of a mixture of methane and xenon in silicalite. Chem Phys Lett 1997, 279 (5-6), 385-388.

29. Goodbody, S. J.; Watanabe, K.; Macgowan, D.; Walton, J. P. R. B.; Quirke, N., Molecular Simulation of Methane and Butane in Silicalite. J Chem Soc Faraday T 1991, 87 (13), 1951-1958.

30. Fritzsche, S.; Karger, J., Tracing memory effects in correlated diffusion anisotropy in MFI-type zeolites by MD simulation. J Phys Chem B 2003, 107 (15), 3515-3521.

31. Hussain, I.; Titiloye, J. O., Molecular dynamics simulations of the adsorption and diffusion behavior of pure and mixed alkanes in silicalite. Microporous and Mesoporous Materials 2005, 85 (1-2), 143-156.

32. Pascual, P.; Ungerer, P.; Tavitian, B.; Boutin, A., Development of a transferable guesthost force field for adsorption of hydrocarbons in zeolites. II. Prediction of alkenes adsorption and alkane/alkene selectivity in silicalite. J Phys Chem B 2004, 108 (1), 393-398.

33. Leroy, F.; Rousseau, B.; Fuchs, A. H., Self-diffusion of n-alkanes in silicalite using molecular dynamics simulation: A comparison between rigid and flexible frameworks. Physical Chemistry Chemical Physics 2004, 6 (4), 775-783. 
34. Kamat, M.; Dang, W. J.; Keffer, D., Agreement between analytical theory and molecular dynamics simulation for adsorption and diffusion in crystalline nanoporous materials. $J$ Phys Chem B 2004, 108 (1), 376-386.

35. Bai, P.; Tsapatsis, M.; Siepmann, J. I., TraPPE-zeo: Transferable Potentials for Phase Equilibria Force Field for All-Silica Zeolites. J Phys Chem C 2013, 117 (46), 24375-24387.

36. Dubbeldam, D.; Calero, S.; Vlugt, T. J. H.; Krishna, R.; Maesen, T. L. M.; Beerdsen, E.; Smit, B., Force field parametrization through fitting on inflection points in isotherms. Phys Rev Lett 2004, 93 (8).

37. Dubbeldam, D.; Calero, S.; Vlugt, T. J. H.; Krishna, R.; Maesen, T. L. M.; Smit, B., United atom force field for alkanes in nanoporous materials. $J$ Phys Chem B 2004, 108 (33), 12301-12313.

38. Martin, M. G.; Thompson, A. P.; Nenoff, T. M., Effect of pressure, membrane thickness, and placement of control volumes on the flux of methane through thin silicalite membranes: A dual control volume grand canonical molecular dynamics study. J Chem Phys 2001, 114 (16), 7174-7181.

39. Demontis, P.; Suffritti, G. B.; Fois, E. S.; Quartieri, S., Molecular-Dynamics Studies on Zeolites .6. Temperature-Dependence of Diffusion of Methane in Silicalite. Journal of Physical Chemistry 1992, 96 (3), 1482-1490.

40. Talu, O.; Myers, A. L., Reference potentials for adsorption of helium, argon, methane, and krypton in high-silica zeolites. Colloids and Surfaces A: Physicochemical and Engineering Aspects 2001, 187, 83-93.

41. June, R. L.; Bell, A. T.; Theodorou, D. N., Molecular dynamics studies of butane and hexane in silicalite. The Journal of Physical Chemistry 1992, 96 (3), 1051-1060.

42. Smit, B., Simulating the adsorption isotherms of methane, ethane, and propane in the zeolite silicalite. The Journal of Physical Chemistry 1995, 99 (15), 5597-5603.

43. Jorgensen, W. L.; Madura, J. D.; Swenson, C. J., Optimized intermolecular potential functions for liquid hydrocarbons. Journal of the American Chemical Society 1984, 106 (22), 6638-6646.

44. Vlugt, T.; Krishna, R.; Smit, B., Molecular simulations of adsorption isotherms for linear and branched alkanes and their mixtures in silicalite. The Journal of Physical Chemistry B 1999, 103 (7), 1102-1118.

45. Martin, M. G.; Siepmann, J. I., Transferable potentials for phase equilibria. 1. Unitedatom description of n-alkanes. The Journal of Physical Chemistry B 1998, 102 (14), 2569-2577.

46. Wang, Y.; Hill, K.; Harris, J. G., Confined thin films of a linear and branched octane. A comparison of the structure and solvation forces using molecular dynamics simulations. The Journal of chemical physics 1994, 100 (4), 3276-3285.

47. Schüring, A.; Auerbach, S. M.; Fritzsche, S.; Haberlandt, R., On entropic barriers for diffusion in zeolites: A molecular dynamics study. The Journal of chemical physics 2002, 116 (24), 10890-10894.

48. Macedonia, M. D.; Maginn, E. J., A biased grand canonical Monte Carlo method for simulating adsorption using all-atom and branched united atom models. Molecular Physics 1999, $96(9), 1375-1390$.

49. Palomino, M.; Corma, A.; Rey, F.; Valencia, S., New Insights on $\mathrm{CO}_{2}-\mathrm{Methane}$ separation using LTA zeolites with different $\mathrm{Si} / \mathrm{Al}$ ratios and a first comparison with MOFs. Langmuir 2010, 26 (3), 1910-1917. 
50. Dunne, J.; Mariwala, R.; Rao, M.; Sircar, S.; Gorte, R.; Myers, A., Calorimetric heats of adsorption and adsorption isotherms. 1. $\mathrm{O}_{2}, \mathrm{~N}_{2}, \mathrm{Ar}, \mathrm{CO}_{2}, \mathrm{CH}_{4}, \mathrm{C}_{2} \mathrm{H}_{6}$, and $\mathrm{SF}_{6}$ on silicalite. Langmuir 1996, 12 (24), 5888-5895.

51. Sun, M. S.; Talu, O.; Shah, D., Adsorption Equilibria of C5- C10 Normal Alkanes in Silicalite Crystals. The Journal of Physical Chemistry 1996, 100 (43), 17276-17280.

52. Zhu, W.; Kapteijn, F.; Moulijn, J., Equilibrium adsorption of light alkanes in silicalite-1 by the inertial microbalance technique. Adsorption 2000, 6 (2), 159-167.

53. Shen, V. K., Siderius, D.W., Krekelberg, W.P., and Hatch, H.W., NIST standard reference simulation website. National Institute of Standards and Technology: Gaithersburg, MD, 20899, 2012.

54. Bridgeman, O. C.; Aldrich, E. W., Vapor Pressure Tables for Water. Journal of Heat Transfer 1964, 86 (2), 279-286.

55. Trzpit, M.; Soulard, M.; Patarin, J.; Desbiens, N.; Cailliez, F.; Boutin, A.; Demachy, I.; Fuchs, A., The effect of local defects on water adsorption in silicalite-1 zeolite: A joint experimental and molecular simulation study. Langmuir 2007, 23 (20), 10131-10139.

56. Jobic, H.; Schmidt, W.; Krause, C. B.; Kärger, J., PFG NMR and QENS diffusion study of n-alkane homologues in MFI-type zeolites. Microporous and mesoporous materials 2006, 90 (1-3), 299-306.

57. Kärger, J.; Ruthven, D. M.; Theodorou, D. N.; Kärger, J.; Krger, J.; Krger, J., Diffusion in Nanoporous Materials. John Wiley \& Sons, Incorporated: Weinheim, GERMANY, 2012. 